\title{
Linking Cell Surface Receptors to Microtubules: Tubulin Folding Cofactor D Mediates Dscam Functions during Neuronal Morphogenesis
}

\author{
Misako Okumura, ${ }^{1}$ Chisako Sakuma, ${ }^{1}$ Masayuki Miura, ${ }^{1,2}$ and Takahiro Chihara ${ }^{1,2}$ \\ ${ }^{1}$ Department of Genetics, Graduate School of Pharmaceutical Sciences, The University of Tokyo, Tokyo, 113-0033, Japan, and ${ }^{2}$ Core Research for \\ Evolutional Science and Technology, Japan Science and Technology Agency, Tokyo, 102-0076, Japan
}

\begin{abstract}
Formation of functional neural networks requires the coordination of cell surface receptors and downstream signaling cascades, which eventually leads to dynamic remodeling of the cytoskeleton. Although a number of guidance receptors affecting actin cytoskeleton remodeling have been identified, it is relatively unknown how microtubule dynamics are regulated by guidance receptors. We used Drosophila olfactory projection neurons to study the molecular mechanisms of neuronal morphogenesis. Dendrites of each projection neuron target a single glomerulus of $\sim 50$ glomeruli in the antennal lobe, and the axons show stereotypical pattern of terminal arborization. In the course of genetic analysis of the dachsous mutant allele $\left(d s^{U A O 71}\right)$, we identified a mutation in the tubulin folding cofactor $D$ gene (TBCD) as a background mutation. TBCD is one of five tubulin-folding cofactors required for the formation of $\alpha$ - and $\beta$-tubulin heterodimers. Single-cell clones of projection neurons homozygous for the TBCD mutation displayed disruption of microtubules, resulting in ectopic arborization of dendrites, and axon degeneration. Interestingly, overexpression of TBCD also resulted in microtubule disruption and ectopic dendrite arborization, suggesting that an optimum level of TBCD is crucial for in vivo neuronal morphogenesis. We further found that TBCD physically interacts with the intracellular domain of Down syndrome cell adhesion molecule (Dscam), which is important for neural development and has been implicated in Down syndrome. Genetic analyses revealed that TBCD cooperates with Dscam in vivo. Our study may offer new insights into the molecular mechanism underlying the altered neural networks in cognitive disabilities of Down syndrome.
\end{abstract}

Key words: axon; dendrite; Drosophila; Dscam; microtubule; tubulin

\section{Introduction}

During development, axons and dendrites elongate toward the proper target region under the guidance of cell surface receptors. The activation of cell surface receptors leads to the modification of cytoskeleton that promotes changes in neuronal morphology. Previous studies have identified a series of actin-binding proteins regulating axon guidance downstream of guidance receptors (Dent et al., 2011). For example, Enabled, the barbed-end binding protein, acts downstream of the repulsive guidance receptor

\footnotetext{
Received March 11, 2014; revised Dec. 10, 2014; accepted Dec. 12, 2014

Author contributions: M.O., C.S., M.M., and T.C. designed research; M.0. performed research; M.O., C.S., and T.C. analyzed data; M.O. and T.C. wrote the paper.

This work was supported by grants from the Ministry of Education, Culture, Sports, Science and Technology in Japan to M.M. and T.C., the Japan Society for the Promotion of Science to M.O., M.M., and T.C., and the Japan Science and Technology Agency to M.M. and T.C. We thank K.D. Irvine (Rutgers University), M.A. Simon (Stanford University), T. Uemura (Kyoto University), H. Matakatsu (University of Winsconsin-Madison), A. Guichet (Institut Jacques Monod), L. Luo (Stanford University), J. Wang (University of Maryland), 0. Schuldiner (Weizmann Institute of Science), the Bloomington Drosophila Stock Center, and the Kyoto Drosophila Genetic Resource (enter for providing the fly stocks,Yasuko Akiyama-Oda and Hiroki Oda (JT Biohistory Research Hall) for the ubi- $\beta$ Tub56D-GFP plasmid, and all the members of Miura laboratory for their kind support and comments.

The authors declare no competing financial interests.

Correspondence should be addressed to Takahiro Chihara, Department of Genetics, The University of Tokyo, 7-3-1 Hongo, Bunkyo-ku, Tokyo, 113-0033, Japan. E-mail: tchihara@mol.f.u-tokyo.ac.jp.

DOI:10.1523/JNEUROSCI.0973-14.2015

Copyright $\odot 2015$ the authors $\quad 0270-6474 / 15 / 351979-12 \$ 15.00 / 0$
}

Roundabout (Bashaw et al., 2000). However, it is still unclear how cell surface receptors and downstream signaling cascades converge to effect the remodeling of cytoskeleton, especially microtubule dynamics.

Microtubules are polymers assembled using heterodimers of $\alpha$ - and $\beta$-tubulins. Five tubulin-folding cofactors A-E (TBCATBCE) assist in the formation of tubulin heterodimers (Tian et al., 1996). The roles of tubulin-folding cofactors have been studied mainly in vitro; however, recent studies have reported ТВСB and TBCE as regulators of neural development and function. Mutations in TBCE cause the hyperparathyroidism-retardationdysmorphism syndrome in humans, and progressive motor neuropathy in mice (Martin et al., 2002; Parvari et al., 2002). Drosophila TBCE is required for the development and function of neuromuscular synapses (Jin et al., 2009), and TBCB knockdown enhances axon growth of neuronal cell lines (Lopez-Fanarraga et al., 2007). However, it is unclear whether tubulin-folding cofactors regulate neuronal morphogenesis by participating in specific cell surface receptor pathways.

We used the Drosophila olfactory system to analyze neuronal morphology. In the antennal lobe, each olfactory projection neuron $(\mathrm{PN})$ targets its dendrites to one of $\sim 50$ glomeruli, and makes synaptic connections with axons of a specific class of olfactory receptor neuron (ORN) (Jefferis and Hummel, 2006; Sakuma et 
al., 2014). Axons of PNs innervate the calyx of the mushroom body, and have a stereotypical pattern of terminal arborization in the lateral horn (Marin et al., 2002; Wong et al., 2002). The target glomeruli of PN dendrites are specified by PN lineages, birth order, and the intrinsic activity of transcription factors (Jefferis et al., 2001; Komiyama et al., 2003; Komiyama and Luo, 2007; Tea et al., 2010). Cell-surface receptors have been identified as regulators of PN axon and dendrite morphogenesis (Zhu and Luo, 2004; Zhu et al., 2006; Komiyama et al., 2007; Hong et al., 2009; Sweeney et al., 2011; Sekine et al., 2013). Thus, PNs provide us with a suitable model for analyzing axon and dendrite morphology in vivo.

During the analysis of the dachsous mutant allele $\left(d s^{U A O 71}\right)$, we identified a mutation in the tubulin folding cofactor $D(T B C D)$ locus as a background mutation. TBCD is required for dendrite morphogenesis and axon maintenance in PNs, along with other tubulin-folding cofactors involved in neuronal morphogenesis. Microtubule networks were disrupted in TBCD mutant PNs. We further found that TBCD interacts with the intracellular domain of Down syndrome cell adhesion molecule (Dscam), which is important for neural development (Hattori et al., 2008). Genetic assays revealed that TBCD cooperates with Dscam during neuronal morphogenesis. Together, we propose that Dscam might modulate microtubule dynamics largely through TBCD function.

\section{Materials and Methods}

Fly strains. Flies were maintained under standard laboratory condition $\left(25^{\circ} \mathrm{C}\right)$. The following mutants and transgenic lines were used: $d s^{U A O 71}$, FRT ${ }^{40 A}$ (Adler et al., 1998), $P\{P Z\} d s^{05142}$ (Spradling et al., 1999), $\mathrm{fat}^{8}$, $F R T^{40 A}$ (Bryant et al., 1988), FRT ${ }^{G 13}, f^{d l}$ (Brodsky and Steller, 1996), $d^{G C 13}, F R T^{40 A}$ (Mao et al., 2006), UAS-ds (Matakatsu and Blair, 2004), UAS-TBCE-RNAi, UAS-TBCE (Jin et al., 2009), FRT ${ }^{G 13}, d T B C B^{1}$ (Baffet et al., 2012), UAS-GFP- $\alpha$ Tub84B (Grieder et al., 2000), UAS-HA-syt (Robinson et al., 2002), FRT ${ }^{G 13}$, Dscam $^{P 1}$ (Wang et al., 2002), UASDscam17.1-GFP, UAS-Dscam17.2-GFP (Wang et al., 2004), Sca-Gal4 (Reddy and Rodrigues, 1999), TBCD ${ }^{1}, F R T^{40 A}$, UAS-TBCD, UASCG11723, UAS-CG4259, UAS- $\beta$ Tub56D-myc, UAS-TBCD-myc, and $U A S$-shRNA-TBCD (in this study). Details of genotypes used in this study are available upon request.

Clonal analysis. We used the mosaic analysis with a repressible cell marker (MARCM) method as described previously (Lee and Luo, 1999). To generate DL1 PNs and mushroom body neuroblast clones, flies with the appropriate genotypes were exposed to a $1 \mathrm{~h}$ heat shock at $0-24 \mathrm{~h}$ after larval hatching. We dissected flies of both male and female aged $<11$ d, with the exception of those described in Figures 3 and 5.

Genetic mapping of TBCD mutant. We performed genetic mapping using single-nucleotide polymorphism-based recombination mapping. This mapping revealed that the mutation responsible for the PN defects in the $d s^{U A O 71}$ MARCM clone is at a cytological location between 22B8 and 23B6. Lethal complementation testing was performed using available deficiency lines within the candidate region. The $d s^{U A O 71}$ mutant failed to complement $D f(2 L) E D 7762, D f(2 L) B S C 688, D f(2 L) E D 125$, $D f(2 L)$ Exel6006, Df(2L)Exel7008, and complemented $D f(2 L)$ Exel7007, $D f(2 L)$ Exel8005, $D f(2 L)$ Exel6007, $D f(2 L)$ Exel7010, suggesting that the mutation is located at the region between 22B8 and 22D1. We performed a lethal complementation test using lines with lethal insertions for the candidate region. $P\{w H y\} D G 14207$ failed to complement $d s^{U A O 71}$, whereas Mi\{MIC\}GlyP[MI00957], P\{EP\}AIF[GE14994],PBac\{RB\}AIF[e04281], and $P\{P Z\} a o p[03953 a]$ complemented $d s^{U A O 71}$. P $\{w H y\} D G 14207$ inserted between CG11723 and CG7261. We constructed UAS-CG11723, UAS-TBCD, and UAS-CG4259 constructs, and found that only the expression of UAS$T B C D$ in $d s^{U A O 71}$ PNs rescued the phenotype. We collected genomic DNA from embryos homozygous for $T B C D^{1}$ and amplified the region of $C G 7261$. A DNA fragment $\sim 9 \mathrm{kbp}$ long was amplified within the coding region of CG7261 by PCR using the following primers: 5'-GCCCTATGCGGAC
AAACTTCTTCAGTGG-3' and 5'-GGAGGGGTACTAGCTCCTCCAAT CGATG-3'.

Construction. To generate $U A S-T B C D$, we obtained a full-length cDNA clone (DGRC clone LD 16031). The cDNA clone was cut by NotI and KpnI and subcloned into the $P U A S T$ vector. Full-length $T B C D$ was amplified from $U A S-T B C D$ using the following primers: $5^{\prime}$-CCTCGAGGTTTATCAGCACTCGCTTGCTGCAAAGCGGC-3' and 5'-CTACTGAAATCTGCCA-3', to make UAS-TBCD-myc. The fragment was cut by NotI and XhoI and subcloned into the $P U A S T-7 x m y c$ vector. To generate UAS-CG11723 and UAS-CG4259, the fragments were amplified from a cDNA library that was extracted from third instar larvae using the following primers: 5'-GCCCGCGAATGGCATACCCGGAGTC-3' and 5'-CTGGTCCACTGCGCCATGAAATCAG-3' for CG11723, and 5'CTGGCTAACTGCCTAAGGC-3' and 5'-CGGAATGTCGCTATA CTTTGCG-3' for CG4259. The PCR product was then subcloned into the $p$ T7Blue vector using TA cloning. The fragment containing the entire cDNA was then cut from the vector using SpeI and BamHI (CG11723), and $\mathrm{XbaI}$ and EcoRI (CG4269), and then subcloned into the pUAST vector. To generate $U A S$-shRNA for $T B C D$, we followed the protocol previously described (Chen et al., 2007). The target sequence of the shRNA is $5^{\prime}$-TGCAGTGGCTGCTATTTTAAAG-3'. The fragment was subcloned into the $p U A S T$-attB vector. To generate UAS- $\beta$ Tub56D-myc, full-length $\beta$ Tub56D was amplified from the $u b i-\beta T u b 56 D-G F P$ plasmid (gifted from Yasuko Akiyama-Oda and Hiroki Oda, JT Biohistory Research Hall, Osaka, Japan) using the following primers: 5'-GCGGCCG CATGCGAGAAATCGTTCACATCC-3' and 5'-CCTCGAGCGTTCTC GTCGACCTCAGCCTCC- $3^{\prime}$. The PCR product was cut by NotI and XhoI and subcloned into the $p U A S T-7 x m y c$ vector. Transgenic flies were raised by BestGene.

Immunostaining. Immunostaining of fly brain was performed as previously described (Wu and Luo, 2006). We used rat anti-mCD8 (1:200; Invitrogen, MCD0800), mouse anti-Bruchpilot [1:40; Developmental Studies Hybridoma Bank (DSHB), nc82], rat anti- $D$ N-cadherin (1:40; DSHB, DNEX-8), mouse anti-myc (1:1000; Invitrogen, 46-0603), rabbit anti-GFP (1:500; MBL, 598), mouse anti-HA (1:1000; Covance, 16B12), PNA-biotin (1:250, J-Oil Mills, J214) and mouse anti-FasII (1:40, DSHB, 1D4). Drosophila S2 cells were cultured on concanavalin A-coated coverslips, fixed, and then immunostained using the following: guinea pig anti-TBCD (1:1000), mouse anti- $\alpha$-tubulin (1:2000; Sigma-Aldrich, DM1A) and rabbit anti-GFP (1:500; MBL, 598). Immunofluorescence signals were acquired using a TCS SP5 or SP8 confocal scanning microscope (Leica), and then processed using Adobe Photoshop.

Generation of TBCD antibody. Polyclonal guinea pig antibody raised against Drosophila TBCD was generated by immunizing a guinea pig with a peptide (MSNSVEECKDEDLPANTLEH) corresponding to the N-terminus of Drosophila TBCD (Biogate Laboratories).

Cell culture and transfection. Drosophila S2 cells were grown at $26^{\circ} \mathrm{C}$ in Schneider's medium supplemented with $10 \%(\mathrm{v} / \mathrm{v})$ heat-inactivated fetal bovine serum, $100 \mathrm{U} / \mathrm{ml}$ penicillin and $100 \mu \mathrm{g} / \mathrm{ml}$ streptomycin. S2 cells in $35 \mathrm{~mm}$ plates $\left(1 \times 10^{6}\right.$ cells per plate $)$ were transfected with $100 \mathrm{ng}$ Actin-Gal4 and desired UAS constructs (150 ng UAS-TBCD-myc, $300 \mathrm{ng}$ UAS-GFP or 300 ng UAS-Dscam17.1-GFP) using Effectene Transfection Reagent (Qiagen, no. 30142). Transfection was performed according to the manufacturer's protocol.

Double-stranded RNA treatment. The design, production, and treatment protocols for double-stranded RNA (dsRNA) were conducted as described previously (Rogers and Rogers, 2008). For control and $T B C D$ dsRNA, primer sequences were used to amplify the sequence from the bacterial cloning plasmids pBluescript SK and UAS-TBCD, respectively. Templates were amplified by PCR using the following primers:

5' -TAATACGACTCACTATAGGTAAATTGTAAGCGTTAATATTTTG- $3^{\prime}$; and

5'-TAATACGACTCACTATAGGAATTCGATATCAAGCTTATCGAT-3' for control; and

5' -TAATACGACTCACTATAGGGGTGGTTTACCTCTCCAACCAACGG-3'; and

5' - TAATACGACTCACTATAGGGCTGTATGCCTGGATGTTCTCGCGG-3' for TBCD. 


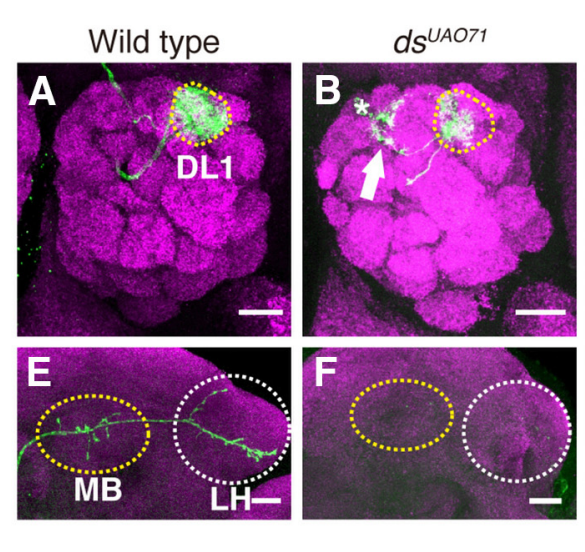

I Dendrite phenotype

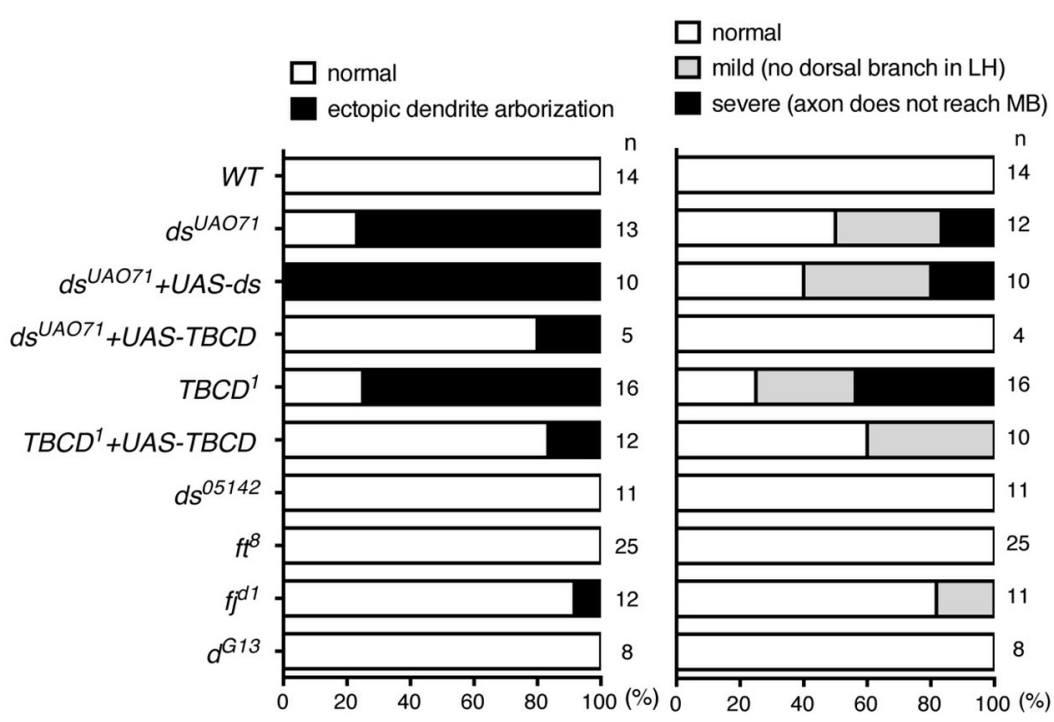

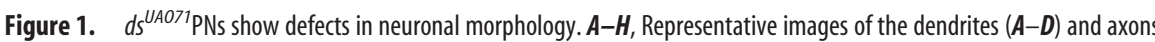
$(\boldsymbol{E}-\boldsymbol{H})$ of DL1 PNs for wild-type $(W T ; \boldsymbol{A}, \boldsymbol{E})$, ds $^{\text {UAO071 }}(\boldsymbol{B}, \boldsymbol{F})$, ds $^{\text {UAO071 }}$ expressing UAS-ds $(\boldsymbol{C}, \boldsymbol{G})$, and ds $\mathrm{s}^{\text {UA071 }}$ expressing UAS-TBCD (D, $\boldsymbol{H})$. All images are confocal $z$-projections. Green indicates morphologies of PNs labeled by mCD8-GFP generated by MARCM using GH146-Gal4. Magenta shows the presynaptic marker Brp. Scale bars, $20 \mu \mathrm{m}$. Asterisks and yellow-dotted circles in $\boldsymbol{A}$ - D denote cell bodies of single-cell clones and the DL1 glomerulus, respectively. Mushroom body (MB) and lateral horn (LH) are marked with yellow and white-dotted circles, respectively in $\boldsymbol{E}-\boldsymbol{H}$. $\boldsymbol{A}$, WT DL1 PN dendrites target the DL1 glomerulus (yellow-dotted circle). $\boldsymbol{B}$, ds ${ }^{\text {UAO71 }}$ single-cell clones showed ectopic dendrite arborization (arrow). $E$, WT DL1 PN axons terminate in the calyx of the MB and the LH. $\boldsymbol{F}$, Axons of $d s^{U A 071}$ mutant single-cell clones did not reach the MB and the LH. $\boldsymbol{C}, \boldsymbol{D}, \boldsymbol{G}, \boldsymbol{H}$, Expression of full-length TBCD but not $d s$ in $d s^{U A O 71}$ mutant single-cell clones rescued the dendrite and the axon phenotypes of $d s^{U A 071}$. I, J, Quantification of the dendrite $(\boldsymbol{I})$ and the axon $(\boldsymbol{J})$ phenotypes in single-cell clones.

S2 cells $\left(1.0 \times 10^{6}\right)$ were cultured in $35 \mathrm{~mm}$ plates; $30 \mu \mathrm{g}$ dsRNA was added every $2 \mathrm{~d}$ for $4 \mathrm{~d}$.

Yeast two-hybrid analysis. Yeast two-hybrid screening was performed by Hybrigenics Services (http://www.hybrigenics-services.com). The coding sequence for full-length Drosophila TBCD (GenBank accession number gi: 28573990) was PCR-amplified and cloned into pB27 as a C-terminal fusion to LexA (N-LexA-TBCD-C) and into pB66 as a C-terminal fusion to Gal4 DNA-binding domain (N-Gal4-TBCD-C). The constructs were checked by sequencing and used as a bait to screen a random-primed Drosophila melanogaster embryo cDNA library constructed into pP6. Cloning vectors pB27, pB66 and pP6 were derived from the original pBTM116 (Vojtek and Hollenberg, 1995), pAS2 $\Delta \Delta$ (Fromont-Racine et al., 1997), and pGADGH (Bartel et al., 1993) plasmids, respectively. For the LexA bait construct, 107 million clones (10fold the complexity of the library) were screened using a mating approach with YHGX13 (Y187 ade2-101::loxP-kanMX-loxP, mata) and as secondary antibodies.

L40 $\Delta$ Gal4 (mata) yeast strains as previously described (Fromont-Racine et al., 1997). A total of 15 His + colonies were selected on a medium lacking tryptophan, leucine, and histidine. For the Gal4 construct, 54 million clones (5-fold the complexity of the library) were screened using the same mating approach with HGX13 (Y187 ade2-101::loxP-kanMXloxP, mata) and CG1945 (mata) yeast strains. A total of $142 \mathrm{His}+$ colonies were selected on a medium lacking tryptophan, leucine, and histidine, and supplemented with $0.5 \mathrm{~mm}$ 3 -aminotriazole to handle bait autoactivation. The prey fragments of the positive clones were amplified by PCR and sequenced at their $5^{\prime}$ and $3^{\prime}$ junctions. The resulting sequences were used to identify the corresponding interacting proteins in the GenBank database (NCBI) using a fully automated procedure. A confidence score (predicted biological score) was attributed to each interaction as previously described (Formstecher et al., 2005).

Immunoprecipitation. S2 Cells in $60 \mathrm{~mm}$ plates $\left(5 \times 10^{6}\right.$ cells per plate $)$ were transfected using the Effectene Transfection Reagent (Qiagen no. 301427). We used isolated plasmid DNA samples in following amounts: $400 \mathrm{ng}$ for Actin-Gal4, $600 \mathrm{ng}$ for UAS-TBCD, and $600 \mathrm{ng}$ for UAS-Dscam17.1-GFP. After transfection, cells were cultured at $26^{\circ} \mathrm{C}$ for $24 \mathrm{~h}$. S2 cells were sonicated in lysis buffer $(25$ mм Tris- $\mathrm{HCl}, \mathrm{pH} 7.9,10 \mathrm{~mm} \mathrm{NaCl}, 2 \mathrm{~mm}$ EDTA, $0.5 \%$ Triton X-100, $10 \mathrm{~mm}$ DTT, and $1 \times$ cOmplete protease inhibitor tablet), and incubated with anti-TBCD antibody (guinea pig, 1:100), anti-GFP antibody (rabbit, 1:333, MBL, 598) or control IgG for $1 \mathrm{~h}$. Protein-G agarose (Roche) was added, and immunoprecipitation was performed according to the manufacturer's protocol.

Immunoblotting. We subjected $1-10 \mu \mathrm{g}$ protein samples of embryo lysates or S2 cell lysates to SDS-PAGE analysis (7.5\% acrylamide gel for TBCD and Dscam-GFP, $12.5 \%$ acrylamide gel for histone H3), and immunoblotting. AntiTBCD antibody (guinea pig; 1:500), anti-GFP antibody (mouse, 1:1000; Roche), and antihistone H3 (rabbit; 1:2000, Active motif, 39163) were used as primary antibodies. Horseradish peroxidase-conjugated antibodies against guinea pig (1:2000; Jackson ImmunoResearch, 706-035-148), mouse (1: 2000; Promega, W02B) and rabbit (1:2000; Cell Signaling Technology, 7074S) were used

Drosophila neuron culture. Drosophila neuron culture from embryos was performed as previously described (Lu et al., 2013). Neurons were incubated at $17^{\circ} \mathrm{C}$ for $18 \mathrm{~h}$ after plating. Cultured neurons were fixed with cold methanol for $5 \mathrm{~min}$ at $-20^{\circ} \mathrm{C}$. Samples were immunostained with mouse anti- $\alpha$-tubulin (1:2000; Sigma-Aldrich, DM1A), rabbit anti-GFP (1:500; MBL, 598), and rat anti-Elav (1:50; DSHB, 7E8A10) antibodies. Measurement of fluorescence intensity was performed using ImageJ.

\section{Results}

TBCD is required for dendrite and axon morphogenesis of PNs

To identify genes involved in neuronal morphogenesis, we performed MARCM-based analysis (Lee and Luo, 1999) using mu- 
A

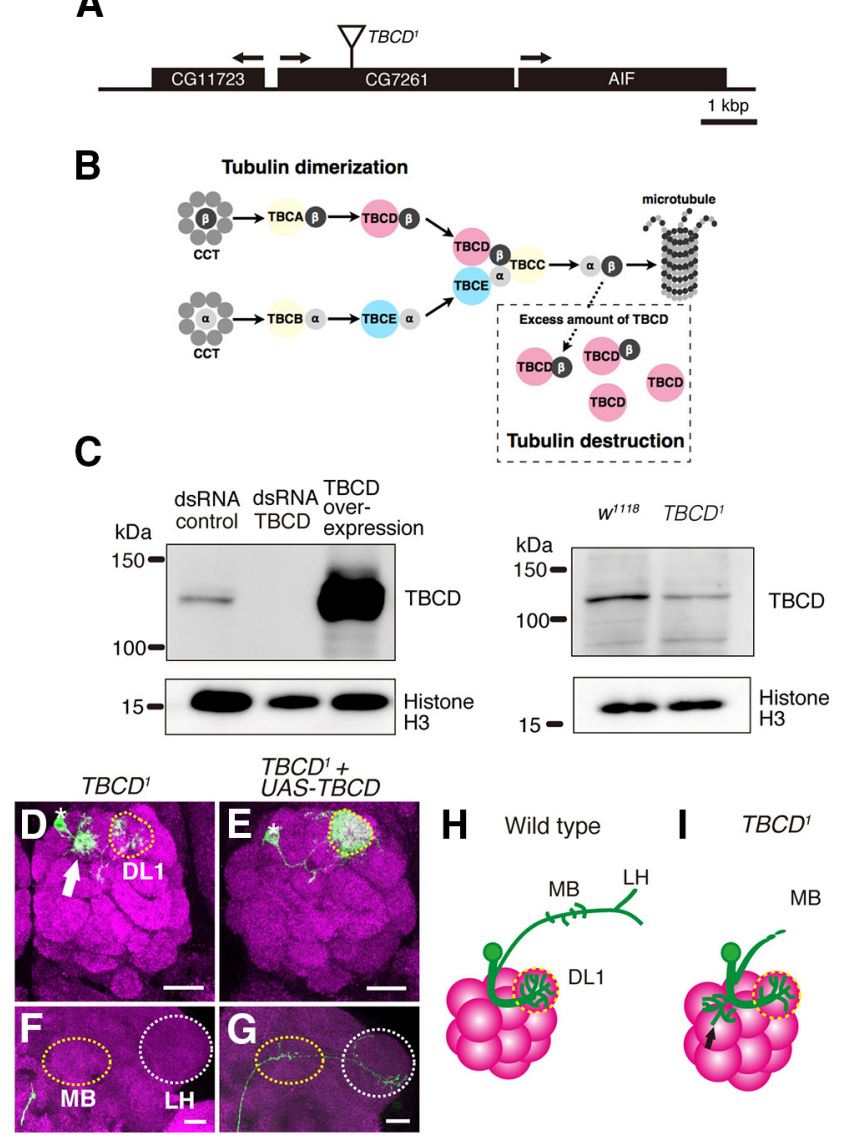

Figure 2. TBCD is required for neuronal morphogenesis of PNs. $A$, Schematic of the CG7261 gene locus, which encodes the Drosophila ortholog of TBCD. The position of the insertion in $T B C D^{7}$ allele is indicated. $\boldsymbol{B}$, Schematic of tubulin-folding pathway. The cytosolic chaperonin CCT is involved in folding of $\alpha$ - (light gray circle) and $\beta$-tubulin (dark gray circle). TBCD interacts with $\beta$-tubulin and assists the formation of tubulin heterodimers. Excess TBCD also interacts with tubulin heterodimers and destabilizes microtubules. C, Western analysis of S2 lysates treated with control and TBCD dsRNA and overexpressing TBCD. The anti-TBCD antibody that we generated recognizes a single band with expected size (134 kDa). Expression of TBCD was reduced in the $T B C D^{1}$ homozygous mutant embryo. $\mathbf{D}-\mathbf{G}$, Images are confocal $z$-projections. Green indicates morphologies of PNs labeled by mCD8-GFP generated by MARCM using GH146Gal4. Magenta shows the presynaptic marker Brp. Scale bars, $20 \mu \mathrm{m}$. Asterisks and yellowdotted circles in $\boldsymbol{D}, \boldsymbol{E}$ denote cell bodies of single-cell clones and the DL1 glomerulus, respectively. MB and $L H$ are marked with yellow and white-dotted circles, respectively in $\boldsymbol{F}, G . \boldsymbol{D}$, $\boldsymbol{F}$, Dendrites $(\boldsymbol{D})$ and axon $(\boldsymbol{F})$ of $T B C D^{7}$ mutant DL1 PNs. Arrow in $\boldsymbol{D}$ shows the ectopic dendrite arborization. $\boldsymbol{E}, \boldsymbol{G}$, Expression of $T B C D$ rescued the defects in the $T B C D^{7}$ mutant. $\boldsymbol{H}, \boldsymbol{I}$, Schematic images of WT $(\boldsymbol{H})$ and $T B C D^{\top}(\boldsymbol{I})$ DL1 single-cell clones. Black arrow in I shows the ectopic dendrite arborization.

tants of planar cell polarity signaling molecules dachsous ( $d s)$, fat $(f t)$, four-jointed ( $f j)$, and dachs $(d)$ as candidates. We found that only the $d s^{U A O 71}$ PNs displayed detectable phenotypes for axon and dendrite morphology. MARCM analysis with GH146-Gal4 and heat shock at $0-24 \mathrm{~h}$ after larval hatching generated singlecell clones of PNs whose dendrites target the DL1 glomerulus (DL1 PN; Fig. 1 A, I; Jefferis et al., 2001). In DL1 PNs homozygous for $d s^{U A O 71}\left(d s^{U A O 71}\right.$ DL1 PNs), dendrites targeted not only the DL1 glomerulus, but also additional glomeruli (Fig. 1 B,I). Axons of wild-type DL1 PNs elongated toward the mushroom body and the lateral horn, and had stereotypical L-shaped pattern of terminal arborization in the lateral horn (Fig. 1 E,J; Marin et al., 2002; Wong et al., 2002). In contrast, axons of $d s^{U A O 71}$ DL1 PNs did not reach the mushroom body and the lateral horn (Fig. $1 F, J$ ). However, three lines of evidence indicate that the mutation in the $d s$ locus does not cause the PN phenotypes observed in $d s^{U A O 71} \mathrm{PN}$ clones. First, the expression of $d s$ cDNA did not rescue the defect in $d s^{U A O 71} \mathrm{PNs}$ (Fig. $1 C, G, I, J$ ). Second, we could genetically segregate $\mathrm{PN}$ phenotypes and $d s$ mutation using meiotic recombination (see Materials and Methods for details). Third, another strong mutant allele, $d s^{05142}$, did not show any defect in PN morphology (Fig. 1I,J). These results suggest that $d s$ is not required for neural morphogenesis in PNs, and the phenotypes of $d s^{U A O 71}$ PNs are caused by a background mutation, rather than a mutation in the $d s$ locus.

To identify the gene responsible for the defects in $d s^{U A O 71} \mathrm{PNs}$, we used genetic mapping methods and reached the conclusion that the gene CG7261 is responsible for the phenotype in $d s^{U A O 71}$ PN clones. First, we found that a DNA fragment $\sim 9 \mathrm{~kb}$ long (probably derived from a natural transposon) was inserted into the coding sequence of the CG7261 locus in the $d s^{U A O 71}$ allele (Fig. 2A). Second, the expression of wild-type CG7261 cDNA in $d s^{U A O 71}$ PN clones could rescue the PN phenotypes of $d s^{U A O 71}$ clones (Fig. $1 \mathrm{D}, \mathrm{H}-\mathrm{J}$ ).

CG7261 encodes a protein orthologous to human TBCD. TBCD is an evolutionarily conserved protein that is essential for the formation of $\alpha$ - and $\beta$-tubulin heterodimers (Fig. 2B; Tian et al., 1996). Because CG7261 is $41.5 \%$ identical and $80.7 \%$ similar to human TBCD, it is likely that the function of TBCD is also evolutionarily conserved. Therefore, we called CG7261 Drosophila TBCD.

We isolated the $T B C D$ mutation from the original $d s^{U A O 71}$ allele by meiotic recombination and referred to this $T B C D \mathrm{mu}-$ tant allele as $T B C D^{1}$. To examine the expression level of TBCD in $T B C D^{1}$, we generated a polyclonal antibody against $\mathrm{N}$-terminal of Drosophila TBCD. Western blot analysis showed that the TBCD antibody specifically recognized TBCD (Fig. 2C, left), and the expression level of TBCD was reduced in the $T B C D^{1}$ homozygous embryo (Fig. $2 \mathrm{C}$, right).

Next, we confirmed the phenotype of the TBCD mutant. $T B C D^{1}$ DL1 PNs exhibited a similar phenotype as $d s^{U A O 71} \mathrm{PNs}$ (Fig. 2D,F,I). Even though the dendrites of $T B C D^{1}$ DL1 PNs targeted the DL1 glomerulus, the number of dendrites innervating the DL1 glomerulus was decreased, and there were ectopic arborizations between the cell body and DL1 glomerulus (Figs. $1 I, 2 D, I)$.

In addition to dendrite defects, $T B C D^{1}$ PNs also showed altered axon morphology. In the wild-type, DL1 PN axons elongated toward the mushroom body and lateral horn and had a stereotypical (L-shaped) pattern in the lateral horn (Figs. $1 E, J$, $2 H)$. TBCD ${ }^{1}$ DL1 PN axons reached neither the mushroom body nor lateral horn (Figs. 1J, 2F,I) or reached the lateral horn without the dorsal branch (data not shown). The defects in $T B C D^{1}$ PNs were rescued by the expression of wild-type $T B C D \mathrm{cDNA}$ (Figs. $1 I, J, 2 E, G$ ). These results suggest that TBCD is cellautonomously required for dendrite and axon morphogenesis in PNs.

Dendrite and axon maintenance were defective in $T B C D^{l}$ PNs To analyze the developmental origin of the $T B C D^{1}$ PN phenotypes, we observed dendrite and axon morphologies of $T B C D^{1}$ PNs during development. Until $18 \mathrm{~h}$ after puparium formation (APF), the PN dendrites elaborate and target the appropriate region in the developing antennal lobe before the arrival of ORN axons $(n=5$; Fig. $3 A$ ). From $48 \mathrm{~h} \mathrm{APF,} \mathrm{PN} \mathrm{dendrites} \mathrm{and} \mathrm{ORN}$ axons are restricted to individual developing glomeruli $(n>8$; Fig. $3 B-D$ ). In $T B C D^{1}$ DL1 PNs, the dendrites targeted the appropriate region at $18 \mathrm{~h} \mathrm{APF}(n=10$; Fig. $3 E)$. However, ectopic 

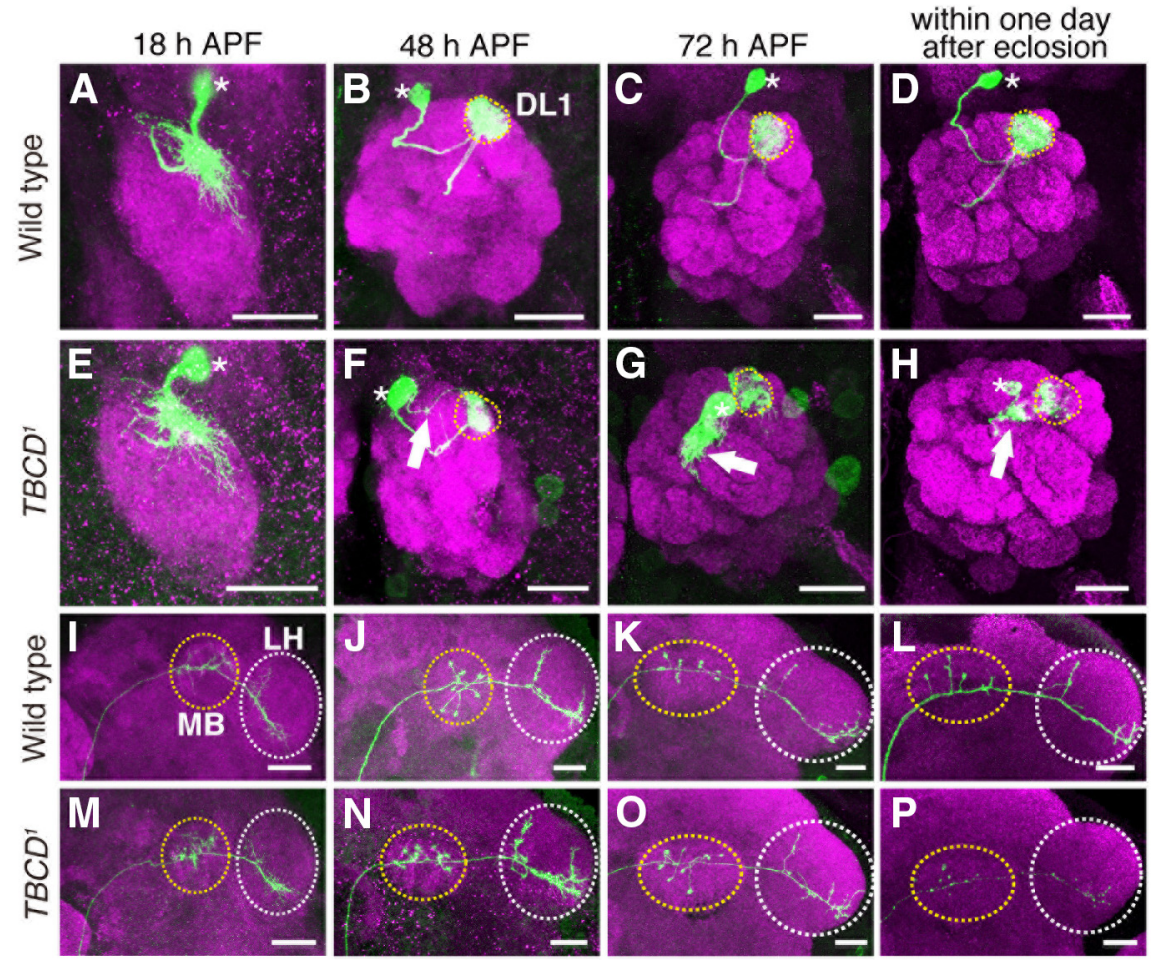

Figure 3. Developmental studies of $T B C D^{1}$ phenotypes. $A-P$, Representative images of DL1 PNs (green) for WT $(\boldsymbol{A}-\boldsymbol{D}, \boldsymbol{I}-\boldsymbol{L})$ and $\operatorname{TBCD}(\boldsymbol{E}-\boldsymbol{H}, \boldsymbol{M}-\boldsymbol{P})$ at $18 \mathrm{~h}(\boldsymbol{A}, \boldsymbol{E}, \boldsymbol{I}, \boldsymbol{M}), 48 \mathrm{~h}(\boldsymbol{B}, \boldsymbol{F}, \boldsymbol{J}, \boldsymbol{N})$, and $72 \mathrm{~h}(\boldsymbol{C}, \boldsymbol{G}, \boldsymbol{K}, \mathbf{O}) \mathrm{APF}$, and within $1 \mathrm{~d}$ after eclosion $(\boldsymbol{D}, \boldsymbol{H}, \boldsymbol{L}, \boldsymbol{P})$. Magenta shows $D N$-Cadherin $(A, B, E, F, I, J, M, N)$, and $\operatorname{Brp}(\boldsymbol{C}, \boldsymbol{D}, \boldsymbol{G}, \boldsymbol{H}, \boldsymbol{K}, \boldsymbol{L}, \boldsymbol{O}, \boldsymbol{P})$ staining. Asterisks, dotted circles, and arrows in $\boldsymbol{A}-\boldsymbol{H}$ indicate cell bodies, the DL1 glomerulus, and ectopic dendrite arborization, respectively. Yellow-dotted circles and white-dotted circles in $\boldsymbol{I}-\boldsymbol{P}$ denote $M B$ and $L H$, respectively. Scale bars, $20 \mu \mathrm{m}$. $\boldsymbol{A}, \boldsymbol{E}$, The dendrites of WT and TBCD ${ }^{1}$ DL1 PNs targeted the appropriate region of the developing AL at $18 \mathrm{~h}$ APF. $\boldsymbol{B}-\boldsymbol{D}$, WT DL1 PN dendrites targeted the DL1 glomerulus (yellow-dotted circles). $\boldsymbol{F}$, At $48 \mathrm{~h} \mathrm{APF}, T B C D^{7}$ DL1 PNs elongated toward the DL1 glomerulus (yellow-dotted circle) and began to form ectopic dendrite arborizations (arrow). $\mathbf{G}, \boldsymbol{H}$, The dendrites of the $T B C D^{1}$ DL1 PN targeted the DL1 glomerulus (yellow-dotted circle) and formed ectopic dendritic arborizations (arrow). $\boldsymbol{I}-\boldsymbol{K}, \boldsymbol{M}-\mathbf{0}$, Until $72 \mathrm{~h}$ APF, axons of WT and $T B C D^{7} \mathrm{PNs}$ elongated toward the MB calyx and the LH and showed typical L-shaped terminal arborization in the LH. L, $P$, Within $1 \mathrm{~d}$ after eclosion, the dorsal branch of $T B C D^{1}$ DL1 PN was lost.

dendrite arborization was observed from $48 \mathrm{~h}$ APF (Fig. 3 F, G, H; $n=3 / 8, n=5 / 7$, and $n=6 / 7$, respectively) suggesting that initial dendrite targeting was not affected in $T B C D^{1} \mathrm{PNs}$, and TBCD is required for the suppression of ectopic dendrite arborization.

The shorter axon phenotype of $T B C D^{l}$ PNs could be caused by failure of axon elongation or maintenance. To examine whether axons of $T B C D^{1}$ PNs elongate properly during development, we observed axon morphology of $T B C D^{l}$ PNs during development. $\mathrm{PN}$ axons elongate and mature during late larval and pupal stages (Jefferis et al., 2004). Until $72 \mathrm{~h} \mathrm{APF,} \mathrm{there} \mathrm{were} \mathrm{no}$ detectable differences in axon morphology between wild-type $(n>4$; Fig. $3 I-K)$ and $T B C D^{1}$ PNs $(n>5$; Fig. $3 M-O)$. The wild-type PNs within $1 \mathrm{~d}$ after eclosion had the stereotypical pattern of L-shaped axon terminal ( $n=7$; Fig. $3 L$ ); however, in $T B C D^{1} \mathrm{PNs}$, the dorsal branch in the lateral horn was lost $(n=$ 2/6; Fig. $3 P$ ). Moreover, $T B C D^{1} \mathrm{PN}$ axons developed swellings, which are typical of axon degeneration. These findings indicate that the axons of $T B C D^{1} \mathrm{PNs}$ elongate, but degenerate at the late pupal and young adult stages and that TBCD is required for axon maintenance in PNs.

Tubulin-folding pathway is required for neuronal morphogenesis in PNs

We then examined whether other tubulin-folding cofactors are required for neuronal morphogenesis. $T B C B^{1}$ mutant clones showed ectopic dendrite arborization, which was comparable to that of $T B C D^{1}$ mutant clones $(n=5 / 25$; Fig. $4 A$ ). Although the penetrance was low, we also observed the loss of dorsal branches in axons of $T B C B^{1}$ PNs ( $n=3 / 25$; Fig. $4 C$ ). Furthermore, we generated DL1 PNs expressing TBCE RNAi. TBCE knockdown resulted in ectopic dendrite arborization $(n=5 / 9$; Fig. $4 B)$, but did not affect axon morphology $(n=8 / 8$; Fig. $4 D)$. We also examined genetic interaction among $T B C D, T B C B$, and TBCE. When we generated $T B C B^{1}$ mutant clones expressing TBCD shRNA, we could hardly obtain single-cell clones. This is probably because tubulin-folding cofactors are important for cell proliferation or cell survival. We also found that expression of $T B C E$ RNAi in $T B C D^{1}$ PNs enhanced the frequency of dendrite defects $(n=9 / 10$ compared with $T B C D^{1}$ PNs, $n=12 / 16$ ). The phenotypic similarities and the genetic interaction among TBCD, TBCB, and TBCE indicate that the tubulinfolding pathway is required for neuronal morphogenesis, especially dendrite morphogenesis.

\section{Microtubules are disrupted in TBCD ${ }^{1}$ PNs}

We expected that the reduced level of TBCD would affect microtubule network formation. To observe microtubule networks in PNs, we generated UAS-myctagged $\beta$ Tub56D and studied its expression in wild-type or $T B C D^{1}$ PNs using the MARCM system. In wild-type DL1 PNs, $\beta$ Tub56D-myc was enriched in the primary branches of dendrites and axons and was less prominent in their terminals $(n=8$; Fig. $5 A, C)$. In contrast, the $\beta$ Tub56D-myc signal disappeared in $T B C D^{1}$ PNs $(n=11$; Fig. $5 B, D)$. We further confirmed the phenotype of microtubules by expressing UAS-GFP- $\alpha$ Tub84B in wild-type or $T B C D^{1}$ PNs. GFP- $\alpha$ Tub84B signal also decreased in $T B C D^{1}$ PNs $(n>5$; Fig. $5 E-P)$. Consistent with the previous study that have shown the microtubule marker disappears before the loss of axons during axon pruning (Watts et al., 2003), the reduction of GFP- $\alpha$ Tub84B signal was observed before the axon degeneration (Fig. $5 K, L, N, O$ ). The failure of microtubuledependent axon transport is a common feature of axon degeneration (Coleman, 2005). To examine whether loss of TBCD affects axon transport, we observed the localization of HA-tagged synaptotagmin (HA-syt), a marker for synaptic vesicles. HA-syt was localized in the presynaptic region of wild-type PNs, where is around the mushroom body and the lateral horn ( $n=7$; Fig. $5 Q)$. In contrast, HA-syt was mislocalized in the axon stalk of $T B C D^{1}$ PNs $(n=8$; Fig. $5 R)$. Together, these results suggest that TBCD is essential for the formation or the maintenance of microtubules in PNs.

Previous studies have shown that TBCD is necessary for the formation of tubulin heterodimers. In addition, overexpression of TBCD results in thinning or obliteration of microtubules in cultured cells (Bhamidipati et al., 2000; Martín et al., 2000; Fig. 

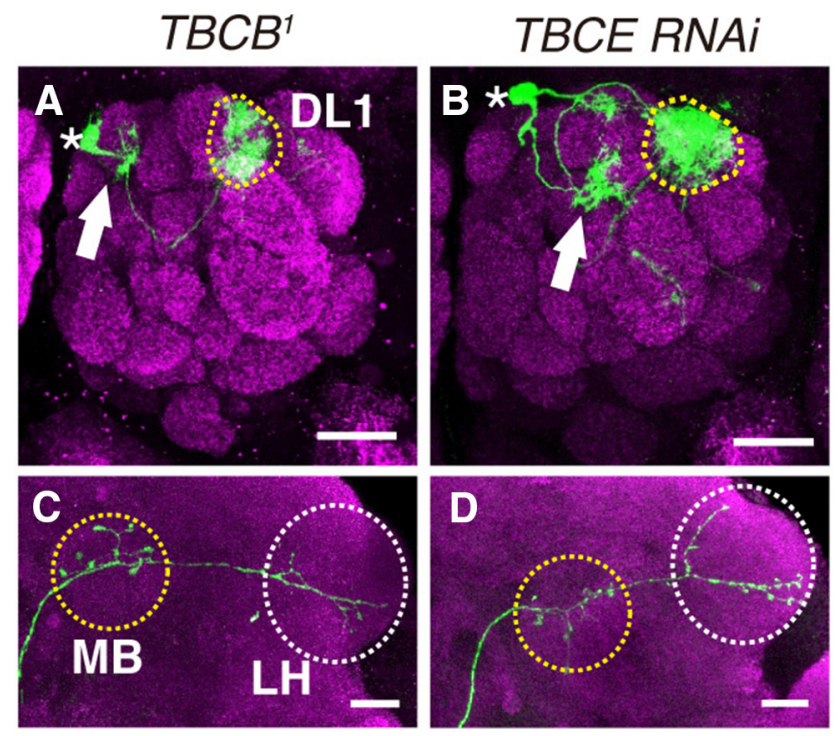

Figure 4. Tubulin-folding pathway is required for dendrite morphogenesis in PNs. $\boldsymbol{A}-\boldsymbol{D}$, Representative images of DL1 PNs homozygous for $\operatorname{TBC}^{1}(A, C)$, or TBCE knockdown $(B, D)$. PN morphologies are labeled with green, and magenta shows Brp staining. Asterisks, dotted circles and arrows in $\boldsymbol{A}, \boldsymbol{B}$ denote cell bodies, the DL1 glomerulus, and ectopic dendrite arborization, respectively. $M B$ and $L H$ are marked with yellow and white-dotted circles, respectively in $C$ and $\boldsymbol{D}$. Scale bars, $20 \mu \mathrm{m} . \boldsymbol{A}, \boldsymbol{B}$, The dendrites of $T B C B^{7}(\boldsymbol{A})$ or TBCE-knockdown $(\boldsymbol{B})$ PNs targeted the DL1 glomerulus and made ectopic arborizations (arrow). $C$, Loss of the dorsal branch in $T B C B^{7}$ DL1 PNs. D, In DL1 PNs expressing TBCE RNAi, axons elongated properly.

$2 B)$. If the disruption to microtubules affects the morphology of PNs, overexpression of TBCD in PNs should cause defects in neuronal morphology. We first examined whether overexpression of Drosophila TBCD causes destruction of microtubules in cultured cells. In S2 cells overexpressing TBCD, a decrease in $\alpha$-tubulin signal was observed (Fig. 6A). To examine whether overexpression of TBCD affects neuronal morphology or not, we analyzed PN clones overexpressing TBCD. When TBCD was overexpressed in DL1 PNs, the dendrites targeted the DL1 glomerulus but made ectopic arborizations, which were similar to the phenotype of $T B C D^{1}$ clones $(n=6 / 7$; Fig. $6 B)$. There were no detectable defects in axon morphology $(n=7 / 7$; Fig. $6 C)$. These results suggest that an optimum amount of TBCD is required for normal dendrite morphology. Consistent with the previous report showing that overexpression of Drosophila TBCE does not disrupt microtubules (Jin et al., 2009), we did not observe defects in neuronal morphology in PNs overexpressing TBCE $(n=7$; Fig. $6 D, E)$. Together, these data imply that TBCD-mediated regulation of the microtubule network is crucial for neuronal morphogenesis, especially for dendrite morphogenesis.

\section{Dscam interacts physically with TBCD}

Recent studies have identified microtubule-associated proteins (MAPs) as participants in specific cell surface receptor pathways (Lee et al., 2004). However, the molecular mechanisms regulating tubulin-folding cofactors during neuronal development have been unclear. To identify the molecules interacting with TBCD, we performed a yeast two-hybrid screen, and found that the intracellular domain of Down syndrome cell adhesion molecule (Dscam) was a candidate for interactions with TBCD (Fig. 7A).

Dscam is a well known regulator of neural development including axon guidance, dendrite self-avoidance, and presynaptic size control (Schmucker et al., 2000; Zhan et al., 2004; Matthews et al., 2007; Cvetkovska et al., 2013; Kim et al., 2013). Dscam is a cell surface molecule with ten Ig domains, six fibronectin type III domains, a transmembrane domain, and an intracellular domain (Schmucker et al., 2000; Fig. 7A). In Drosophila, alternative splicing of three Ig domains and the transmembrane domain can give 38,016 isoforms (Schmucker et al., 2000). Each isoform binds other identical isoforms and mediates homophilic repulsion (Wojtowicz et al., 2004; Hattori et al., 2007). In addition, Dscam also acts as a Netrin receptor, thereby mediating axon guidance (Andrews et al., 2008; Ly et al., 2008).

To confirm the physical interaction between TBCD and Dscam we performed a coimmunoprecipitation experiment. Anti-TBCD antibody could coprecipitate TBCD with DscamGFP from the lysate of S2 cells expressing TBCD and Dscam-GFP (Fig. $7 B$, left). We could further confirm this interaction by immunoprecipitating Dscam-GFP with anti-GFP antibody (Fig. 7B, right). These results indicate that TBCD and Dscam physically interact with each other.

\section{TBCD cooperates with Dscam in PNs}

To examine whether TBCD regulates neuronal morphogenesis by acting cooperatively with Dscam, we performed genetic analysis using TBCD and Dscam. We generated DL1 PNs for Dscam ${ }^{P 1}$ homozygous mutants (Dscam ${ }^{P 1}$ DL1 PNs) on a $T B C D^{1}$ heterozygous background. Although the dendrites of DL1 PNs for all of the four genotypes targeted the DL1 glomerulus, the dendrites tended to spill over to the outside of the antennal lobe (Fig. $7 E-$ $H)$. We classified the phenotypes into three groups according to severity, and found that the spill-over phenotype was enhanced in $D_{\text {scam }}{ }^{P 1}$ DL1 PNs on a TBCD ${ }^{1}$ heterozygous background (Fig. $7 C, H)$. Axon of $D_{s c a m}{ }^{P 1}$ DL1 PNs caused loss of the dorsal branch in the lateral horn (Fig. $7 K$ ). Dscam $^{P 1}$ DL1 PNs on a $T B C D^{1}$ heterozygous background also showed the loss of the dorsal branch in the lateral horn but did not enhance the defect of Dscam $^{P l}$ DL1 PNs (Fig. $\left.7 D, I-L\right)$.

Next we overexpressed Dscam-GFP in PNs and found that ectopic dendrite arborization $(n=6 / 7$; Fig. $7 M)$ and loss of the dorsal branch in the lateral horns $(n=5 / 7$; Fig. $7 N)$. Thus, the increased amount of Dscam exhibited dendrite morphological defects in PNs, which is similar to those observed in PNs homozygous for $T B C D^{1}$ or overexpressing $T B C D$ (Figs. $2 D, 6 B$ ). These genetic data suggest that TBCD cooperates with Dscam in dendrite morphogenesis of PNs.

\section{TBCD cooperates with Dscam in mushroom body neurons}

To confirm the interaction between TBCD and Dscam we used another type of neuron, the mushroom body neurons. Mushroom body is an olfactory learning and memory center (Heisenberg, 2003) and consists of three types of neurons, $\alpha / \beta, \alpha^{\prime} / \beta^{\prime}$, and $\gamma$ neurons (Lee et al., 1999). $\alpha / \beta$ neurons extend one axon into $\alpha$ lobe and the other axon into $\beta$ lobe, that are labeled by anti-FasII antibody (Fig. $8 \mathrm{~A}, \mathrm{C}$ ). Dscam is required for segregation of sister branches of $\alpha / \beta$ neurons (Wang et al., 2002; Fig. $8 B$ ). To test whether TBCD is involved in the development of mushroom body neurons, we expressed short-hairpin RNA for TBCD ( $\operatorname{sh} R A-T B C D)$ in all mushroom body neurons with OK107Gal4 driver. Knockdown of TBCD caused a loss of the $\beta$ lobe and a thickened $\alpha$ lobe, which is similar to the defect in the Dscam mutant (Fig. 8B,D). Next, we hypothesized that TBCD and Dscam works in the same pathway. If TBCD acts downstream of Dscam, knockdown of TBCD would suppress the phenotype of Dscam overexpression. When Dscam was overexpressed in mushroom body neurons with OK107-Gal4, $\alpha$ and $\beta$ lobes were missing (Wang et al., 2004; Fig. 8E,H). However, when shRNA- 


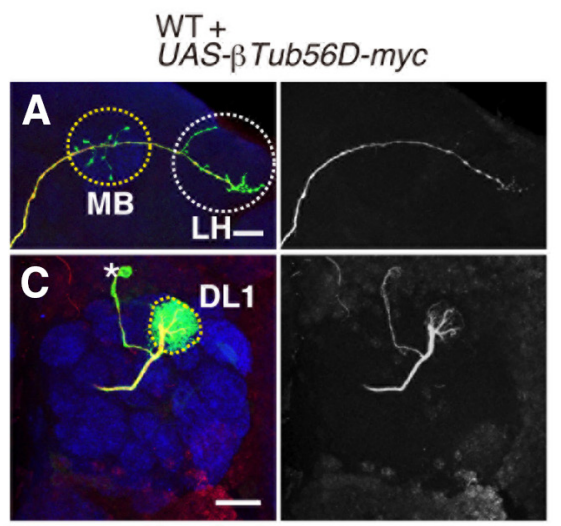

GFP myc DN-cadherin

72 h APF
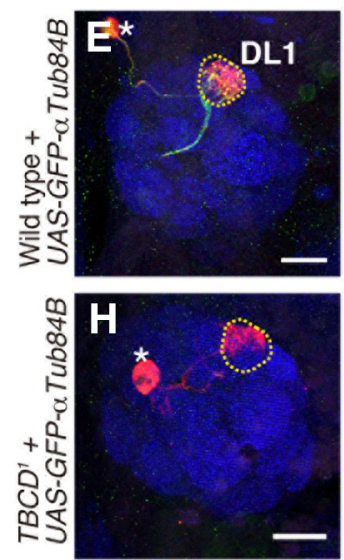

GFP mCD8 PNA
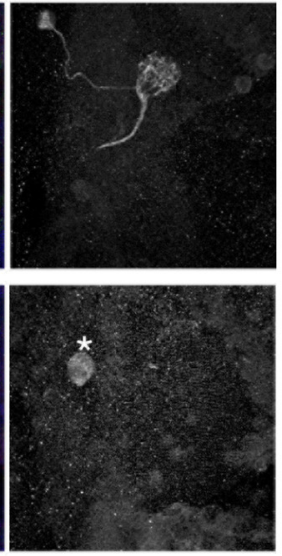

GFP

72 h APF
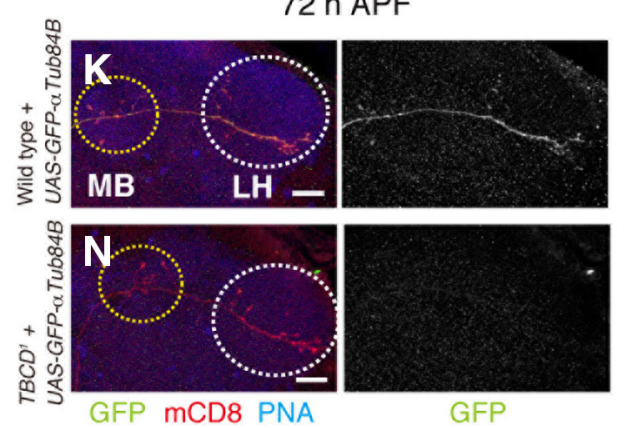

GFP

Wild type + UAS-HA-syt

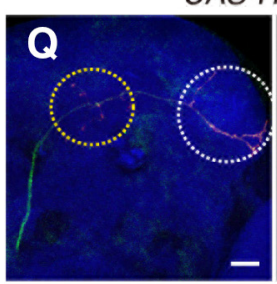

mCD8 HA PNA

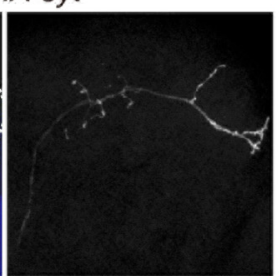

HA

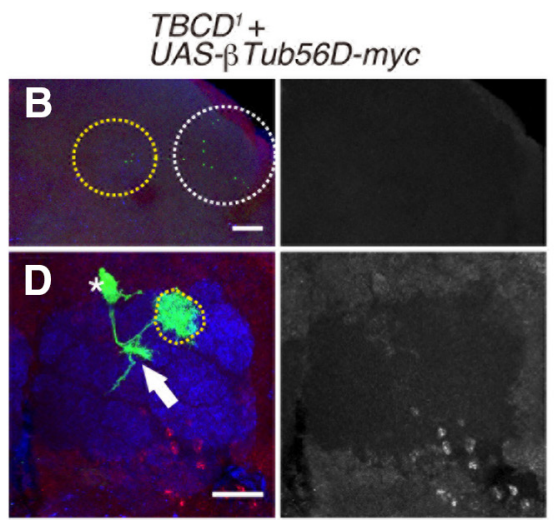

GFP myc DN-cadherin

within one day after eclosion
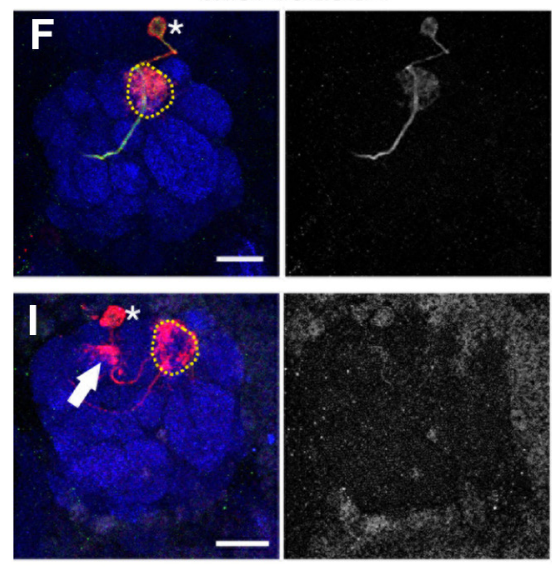

GFP mCD8 PNA

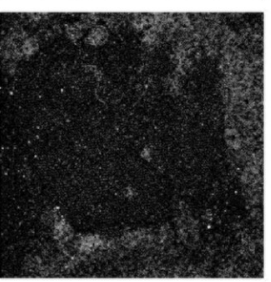

GFP

within one day after eclosion
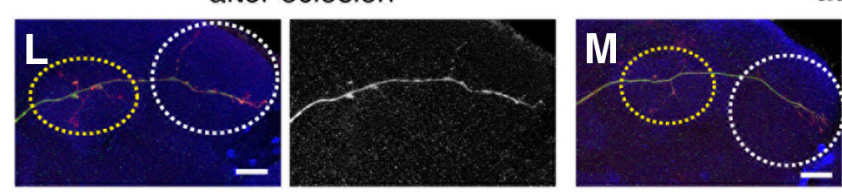

adult

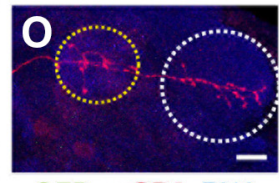

GFP mCD8 PNA

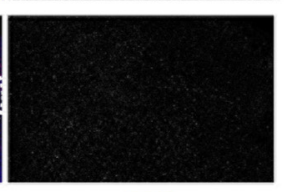

GFP

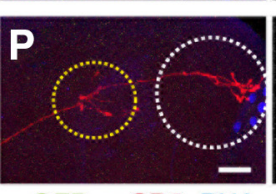

GFP mCD8 PNA
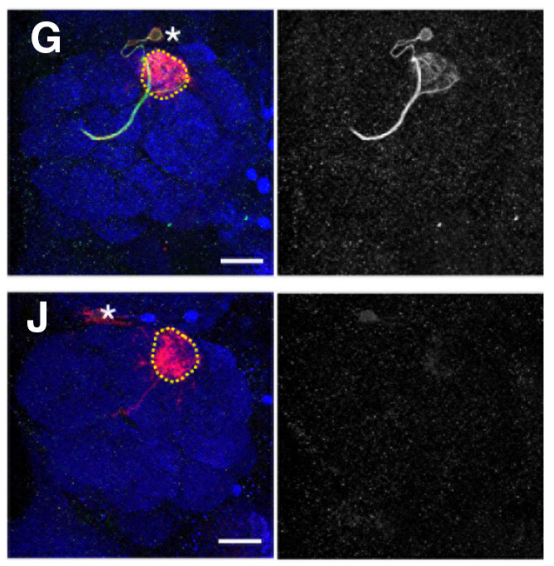

GFP mCD8 PNA

GFP

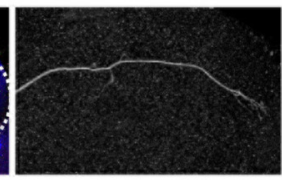

$T B C D^{1}+$

UAS-HA-syt

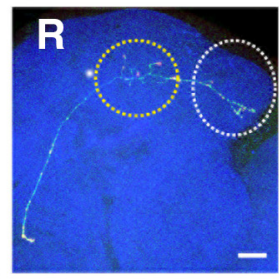

mCD8 HA PNA

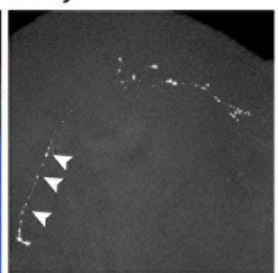

HA

Figure 5. Absence of tubulin labeling in $T B C D^{7}$ PNs. $A-D, U A S-\beta T$ Tub56D-mycwas expressed in WT $(A, C)$ and $T B C D^{1}(B, D)$ DL1 PNs. PN morphologies are labeled in green, red shows $\beta$ Tub56D-mycstaining, and blue shows anti-DN-cadherin staining.A, C, $\beta$ Tub56D-myc is present throughout the axons and dendrites of WT DL1 PNs. B, D, No $\beta$ Tub56D-myc labeling detected in TBCD DL1 PNs. E-P, Representative images of dendrite $(\boldsymbol{E}-\boldsymbol{J})$ and axon $(\boldsymbol{K}-\boldsymbol{P})$ of DL1 PNs expressing UAS-GFP- $\alpha$ Tub84B in WT $(\boldsymbol{E}-\mathbf{G}, \boldsymbol{K}-\boldsymbol{M})$ and $T B C D^{\top}(\boldsymbol{H}-\boldsymbol{J}, \boldsymbol{N}-\boldsymbol{P})$ at $72 \mathrm{~h} \mathrm{APF}(\boldsymbol{E}, \boldsymbol{H}, \boldsymbol{K}, \boldsymbol{N})$, within 1 dafter eclosion $(\boldsymbol{F}, \boldsymbol{I}, \boldsymbol{L}, \mathbf{0})$ and $7-10$ dadult $(\boldsymbol{G}$, $\boldsymbol{J}, \boldsymbol{M}, \boldsymbol{P})$. PN morphologies are labeled in red, green shows GFP- $\alpha$ Tub84B staining, and blue shows PNA-biotin staining. $\mathbf{Q}, \boldsymbol{R}$, UAS-HA-syt was expressed in WT $(\mathbf{Q})$ and $T B C D^{1}(\boldsymbol{R})$ DL1 PNs. $\mathbf{Q}, \mathrm{HA}-\mathrm{syt}$ normally accumulates in presynapticsites, the calyx of the MB and the LH. $\boldsymbol{R}$, HA-sytmislocalizes at the stalk of axon (arrowheads). MB and LH are marked withyellow and white-dotted circles, respectively in $\boldsymbol{A}, \boldsymbol{B}$, and $\boldsymbol{K}$ - $\boldsymbol{R}$. Asterisks, dotted circles, and arrows in C $-J$ denote cell bodies, the DL1 glomerulus, and ectopic dendrite arborization, respectively. Scar bars, $20 \mu \mathrm{m}$. 

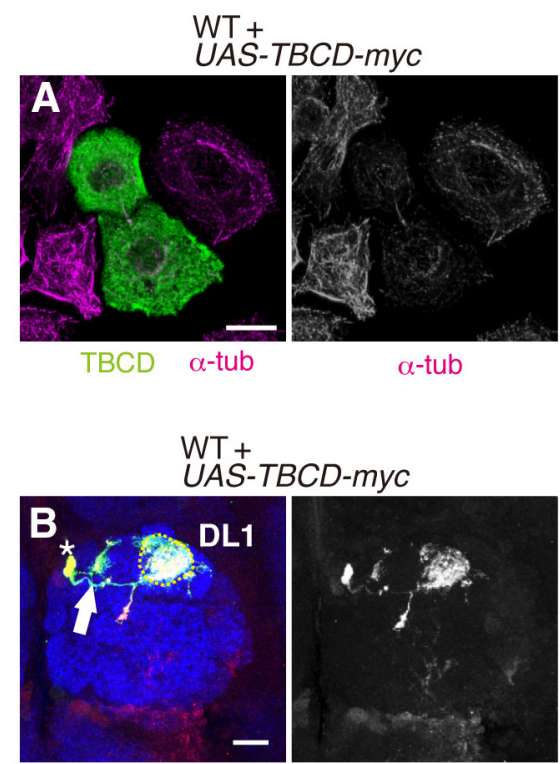

BCD-myc
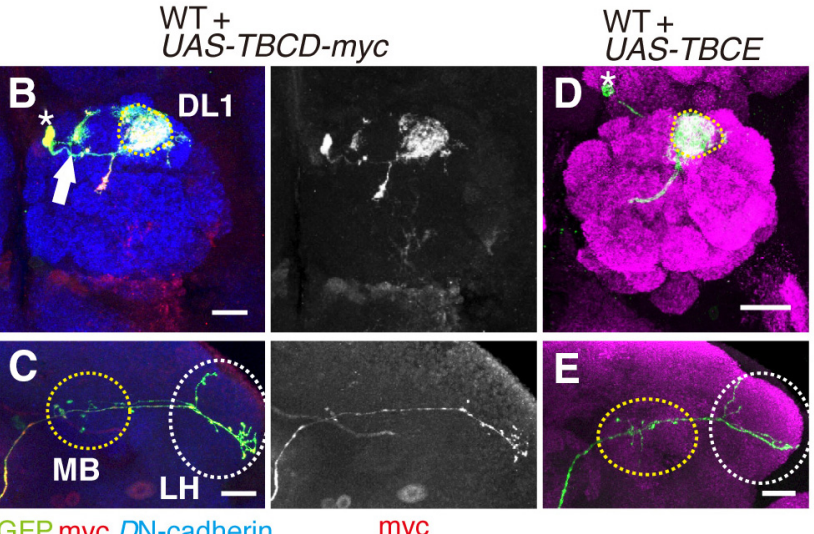

GFP myc DN-cadherin

myc

Figure 6. Overexpression of TBCD affects dendrite morphology of PNs. $\boldsymbol{A}, \mathrm{TBCD}$ was transfected in $\mathrm{S} 2$ cells. Green shows anti-TBCD antibody staining. Magenta shows anti- $\alpha$-tubulin antibody staining to detect microtubule network. The staining of microtubules was decreased in S2 cells overexpressing TBCD. Scale bar, $10 \mu \mathrm{m} . \boldsymbol{B}, \boldsymbol{C}$, In DL1 PNs overexpressing TBCD-myC, the dendrites innervate the DL1 glomerulus and additional glomeruli ( $\boldsymbol{B}$, arrow). Asterisk and dotted circle in $\boldsymbol{B}$ denote cell body and the DL1 glomerulus. Overexpression of TBCD-myc in WT DL1 PNs did not affect axonal morphology ( $\boldsymbol{C}$, green). Anti-myc antibody staining is shown in red. Blue indicates anti-DN-cadherin staining. $M B$ and $L H$ are marked with yellow and whitedotted circles, respectively in C. Scale bars, $20 \mu \mathrm{m}$. D, E, Overexpression of TBCE in DL1 PNs did not affect dendrite $(\boldsymbol{D})$ and axon $(\boldsymbol{E})$ morphology. PN morphologies are labeled with green, and magenta shows Brp staining. MB and LH are marked with yellow and white-dotted circles, respectively in $\boldsymbol{E}$.

TBCD and Dscam-GFP were overexpressed simultaneously, the frequency of loss of $\alpha$ and $\beta$ lobes was significantly decreased (Fig. $8 F, H$ ). We further found that $T B C D^{1}$ heterozygous background suppressed the Dscam overexpression phenotype (Fig. $8 G, H)$. These results suggest that the Dscam overexpression phenotype in mushroom body is caused by increased activity or amount of TBCD.

We also examined the effects of Dscam overexpression on microtubule in S2 cells and Drosophila primary cultured neurons. We stained $\alpha$-tubulin of S2 cells transfected with UAS-DscamGFP or UAS-GFP as a control (Fig. 8I-K). Overexpression of Dscam-GFP caused the reduction of $\alpha$-tubulin staining at the cell periphery of S2 cells (Fig. 8J,K). Similar results were obtained with Drosophila primary cultured neurons from dissociated embryos at stage 11 . Along the axons of cultured neurons, $\alpha$-tubulin was decreased at the site where Dscam-GFP was accumulated (Fig. $8 L-N$ ). These results support the idea that overexpression of Dscam causes the reduction of $\alpha$-tubulin through TBCD, and TBCD cooperates with Dscam in neuronal morphogenesis.

\section{Discussion}

In this study, we have analyzed the function of TBCD in neuronal morphogenesis using PNs and mushroom body neurons. TBCD and other tubulin-folding cofactors are required for in vivo den- drite morphogenesis. We have also revealed the physical interactions between TBCD and Dscam, and shown that TBCD cooperates with Dscam in dendrite morphogenesis in PNs and axon segregation in mushroom body neurons.

The roles of tubulin-folding cofactors have been mainly studied in vitro, but recently TBCB and TBCE have been shown to be regulators of neural development and function (LopezFanarraga et al., 2007; Schaefer et al., 2007; Jin et al., 2009). Our study provides in vivo evidence that tubulin-folding cofactors are required for neuronal morphogenesis. An increase or a decrease in the amount of TBCD caused ectopic arborization of dendrites in PNs. Mutation of TBCD in PNs also led to the destruction of microtubules and axon degeneration. Our results suggest that microtubule networks mediated by tubulin-folding cofactors are important for suppression of ectopic dendrite arborization, and for axon maintenance. In addition to the role of a tubulin chaperone, TBCD is also used for recruitment of the $\gamma$-tubulin ring complex at centrosomes, a microtubule-organizing center in HeLa cells (Cunningham and Kahn, 2008). Depletion of TBCD in the centrosomes might affect neuronal morphology. Further studies on the precise subcellular localization of TBCD in neurons would provide a better understanding of TBCD functions in neuronal morphogenesis.

TBCE knockdown in PNs led to the ectopic arborization of dendrites, but not to axon degeneration. This result may have been due to knockdown efficiency of TBCE that was insufficient to reveal the true phenotype regarding axon degeneration. Another possibility is that the axon degeneration resulting from TBCE knockdown may occur in older flies, as TBCE mutation causes progressive motor neuropathy, which results in axon degeneration 4-5 weeks after birth (Schmalbruch et al., 1991).

We have also identified Dscam as an interacting partner of TBCD. It is likely that TBCD functions downstream of Dscam and propagates signals from Dscam to effect changes in microtubule dynamics. Dscam has multiple functions in neural development, acting as a homophilic repulsive molecule and also an attractive receptor stimulated by Netrin (Hattori et al., 2008; Ly et al., 2008). Although Dscam has been studied extensively, the pathways acting downstream of Dscam are not well known. One known pathway is the Dock/Pak signaling. Drosophila Dscam was initially identified as a Dock-binding protein (Schmucker et al., 2000). DSH3PX, one of the sorting nexins, connects Dscam to the actin cytoskeleton by interacting with Dock, Dscam, and Wasp. Wasp is a component of the actin polymerization machinery (Worby et al., 2001). The intracellular domain of Dscam is not well conserved, but the mammalian homolog of Dscam (DSCAM) binds and activates p21-Activated Kinase 1 (PAK1; Li and Guan, 2004). Therefore, the downstream signal is likely to be evolutionarily conserved. Interestingly, PAK1 phosphorylates human TBCB, and knockdown of TBCB or PAK1 reduces microtubule polymerization, suggesting that the phosphorylation of TBCB by PAK1 might be necessary for the function of TBCB (Vadlamudi et al., 2005). Therefore, in mammals, the tubulinfolding pathway may work downstream of DSCAM by interacting with PAK1. However, in Drosophila PNs, Dock and Pak are not considered necessary for dendrite targeting and axon guidance (Sekine et al., 2013). TBCD is likely to act downstream of Dscam independently from the Dock/Pak pathway in dendrite morphogenesis of PNs.

Regulation of microtubule dynamics has been well studied and many MAPs have been identified. Recent studies have suggested that cell surface receptors and their downstream signaling cascades also regulate microtubule dynamics. For example, the 


\section{A Dscam domain structure}

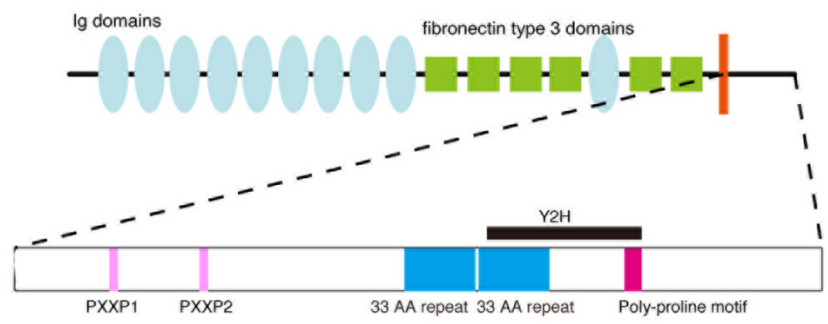

RSKGNHHKDDVVYNQTMGPGATLDKRRPDLRDELGYIAPPNRKLPPVPGSNYNTCDRIKRGRGGLRS NHSTWDPRRNPNLYEELKAPPVPMGGNYGHAHGNAECHYRHPGMEDEICPYATFHLLGFREEMDPT KAMNFQTFPHQNGHAGPVPGHAGTMLPPGHPGHVHSRSGSOSMPRANRYQRKNSQGGQSSIYTPA PEYDDPANCAEEDQYRRYTRVNSQGGSLYSGPGPEYDDPANCAPEEDOYGSOYGGPYGQPYDHYG SRGSMGRRSIGSARNPGNGSPEPPPPPPRNHDMSNSSFNDSKESNEISEAECDRDHGPRGNYGAVK RSPQPKDQRTTEEMRKLIERNETGPKOLQLQQANGAGFTAYDTMAV

\section{B}
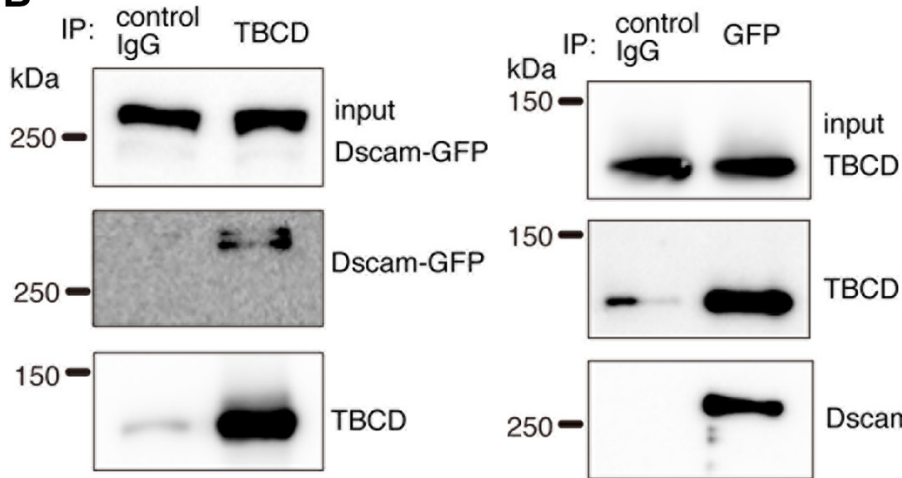

TBCD

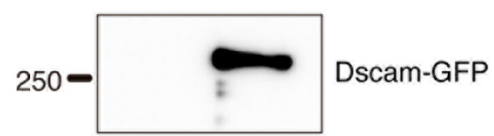

\section{Dendrite spill-over phenotype}

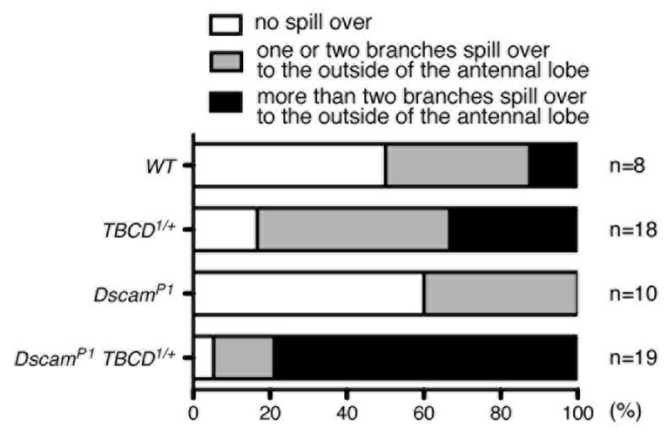

D Axon phenotype

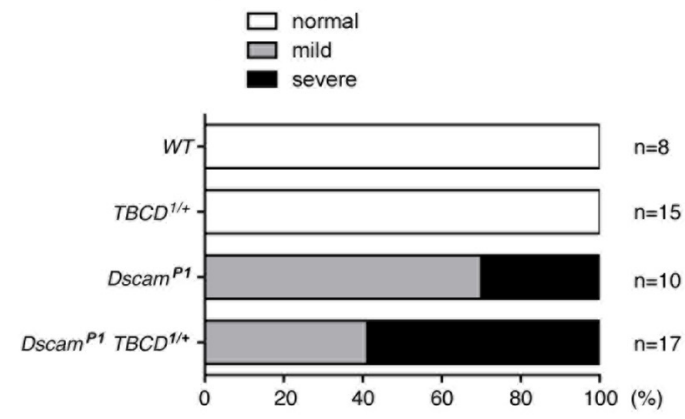

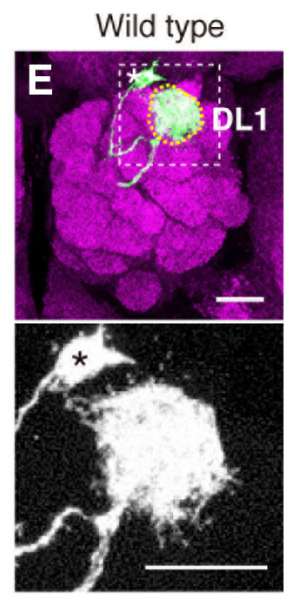
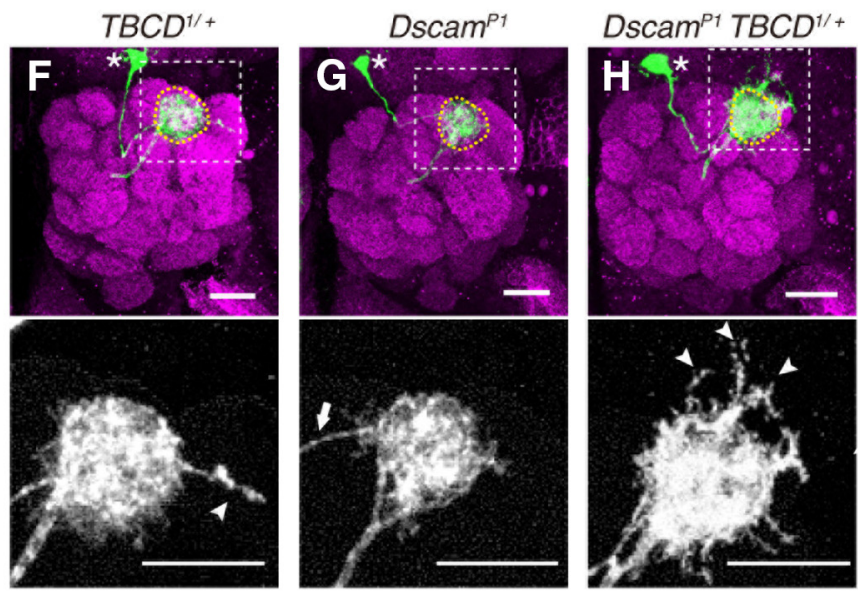

WT +
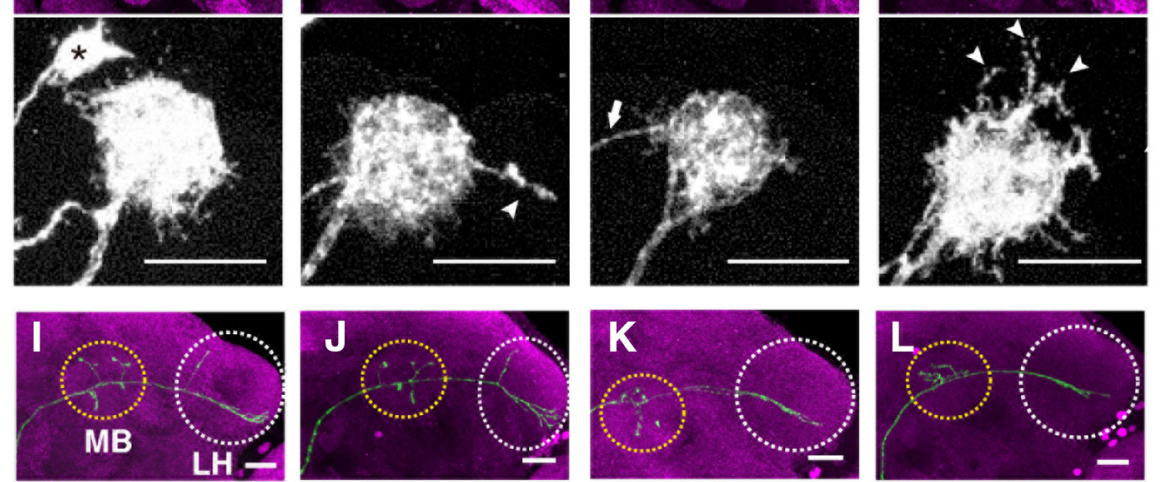

UAS-Dscam17.1-GFP
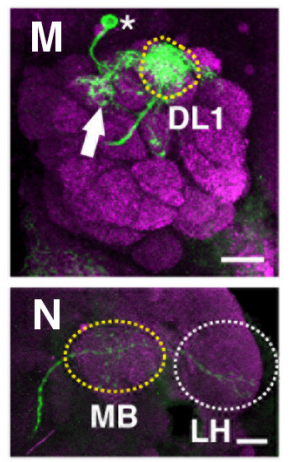

Figure 7. TBCD and Dscam form a complex and cooperate with each other in dendrite morphogenesis of PNs.A, Scheme of Dscam domain structure. Dscam has ten Ig domains (light blue ellipses), six fibronectin type III domains (green squares), a single transmembrane domain (orange bar), and a (-terminal cytoplasmic domain. Ig domains 2, 3, and 7, and the transmembrane domain have alternative splice variants. The cytoplasmic domain is shown in detail; PXXP domains (pink), 33 aa repeats (blue), and poly-proline motif (magenta). The candidate region interacting with TBCD is underlined in the sequence. $\boldsymbol{B}$, Western blot analysis of $\mathbf{S} 2$ lysates immunoprecipitated using anti-TBCD and anti-GFP. C, Quantification of the dendrite spill-over phenotype. $\boldsymbol{D}$, Quantification of the axon phenotype. $\boldsymbol{E}-\boldsymbol{L}$, Representative images of DL1 PNs of WT clones $(\boldsymbol{E}, \boldsymbol{I})$; WT clones on $T B C D^{1}$ heterozygous background $(\boldsymbol{F}, \boldsymbol{J})$; Dscam ${ }^{P 1}$ homozygous mutant clones $(\boldsymbol{G}, \boldsymbol{K})$; and $D$ scam ${ }^{P 1}$ homozygous mutant clones on $T B C D^{7}$ heterozygous background $(\boldsymbol{H}, \boldsymbol{L})$. PN morphologies are labeled with green, and magenta shows Brp staining. Asterisks and dotted circles in $\boldsymbol{E}-\boldsymbol{H}$ denote cell bodies and the DL1 glomerulus, respectively. Arrowheads denote the dendrites that extend beyond the antennal lobe $(\boldsymbol{F}, \boldsymbol{H}$, bottom). MB and $\mathrm{LH}$ are marked with yellow and white-dotted circles, respectively in I-L. Scale bars, $20 \mu \mathrm{m}$. $\boldsymbol{F}, \boldsymbol{G}$, The dendrites of DL1 PNs for $T B C D^{1}$ heterozygous and Dscam ${ }^{P 1}$ targeted the DL1 glomerulus. Arrow shows the dendrite from the cell body $(\boldsymbol{G})$. $\boldsymbol{H}$, The dendrite spill-over phenotype was enhanced in Dscam ${ }^{P 1}$ homozygous mutant clones on $T B C D^{1}$ heterozygous background. $I, J$, In DL1 PNs for WT $(I)$ and $T B C D^{1}$ heterozygous $(\boldsymbol{J})$, axons innervated

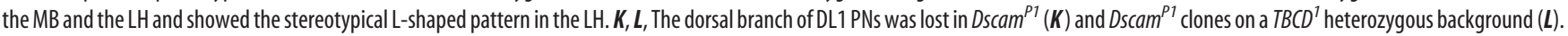
$M, N$, In DL1 PNs overexpressing Dscam 17.1-GFP, the dendrites innervate the DL1 glomerulus (yellow-dotted circle) and additional glomeruli ( $M$, arrow), and the axon does not form the dorsal branch at the $\mathrm{LH}(\boldsymbol{N})$. 


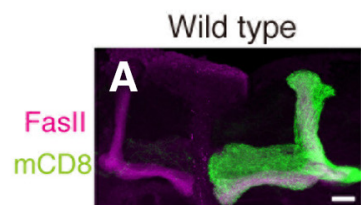

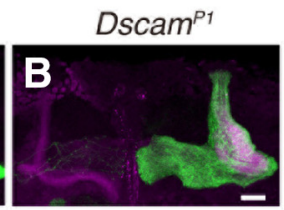

Wild type
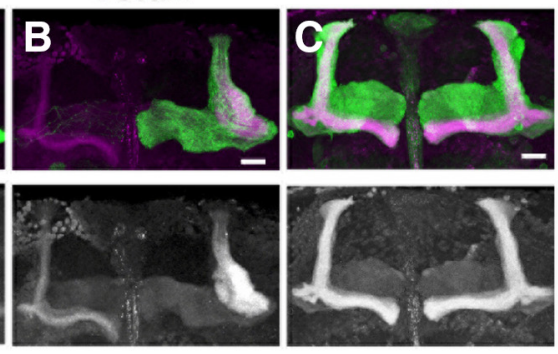

ShRNA-TBCD
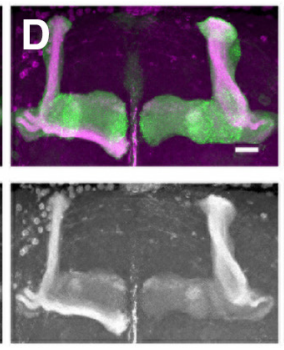

Dscam17.2-GFP
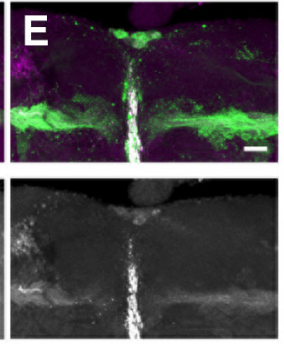
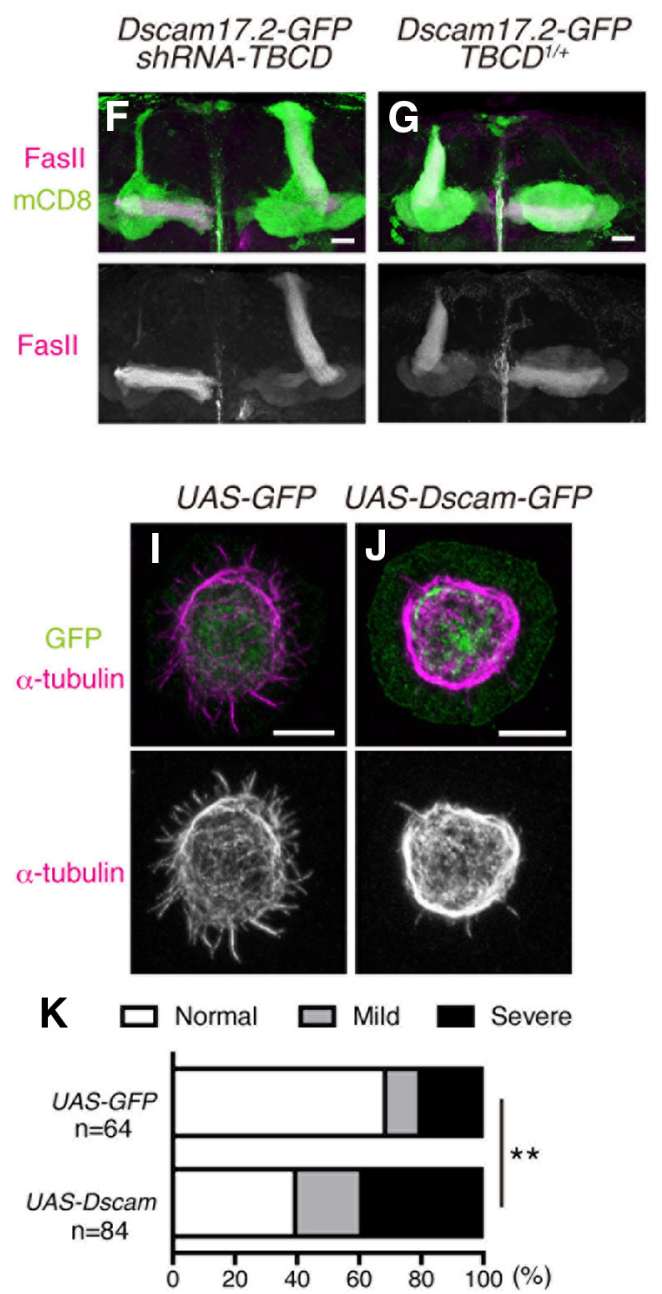

H
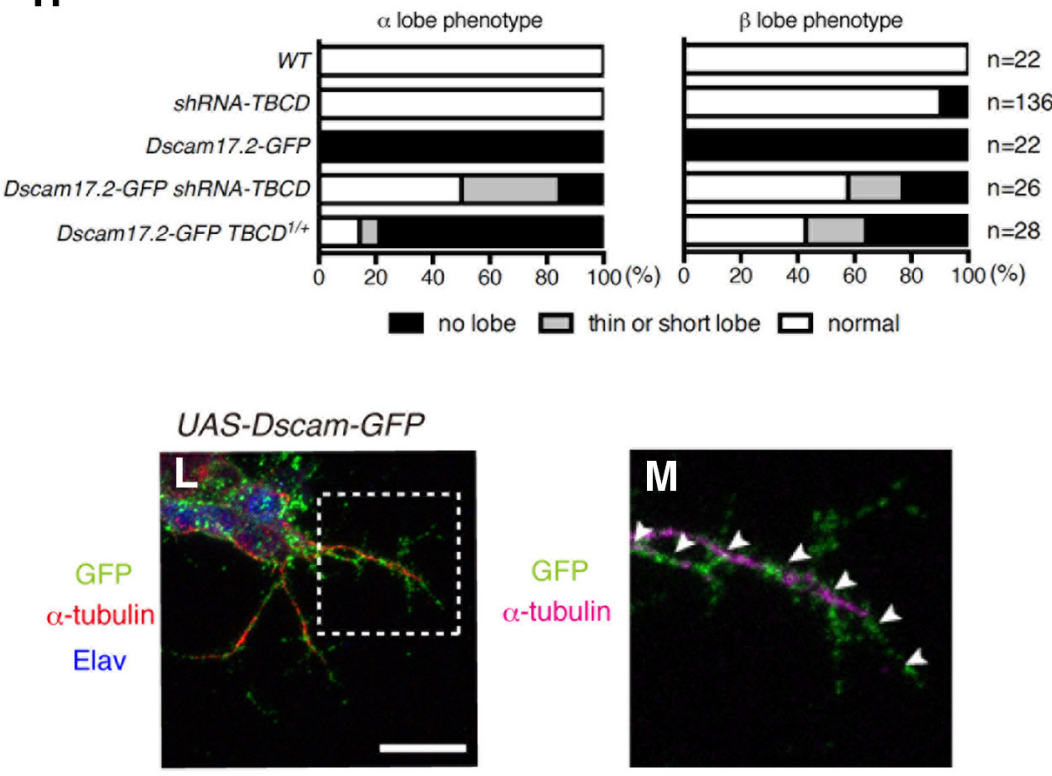

N

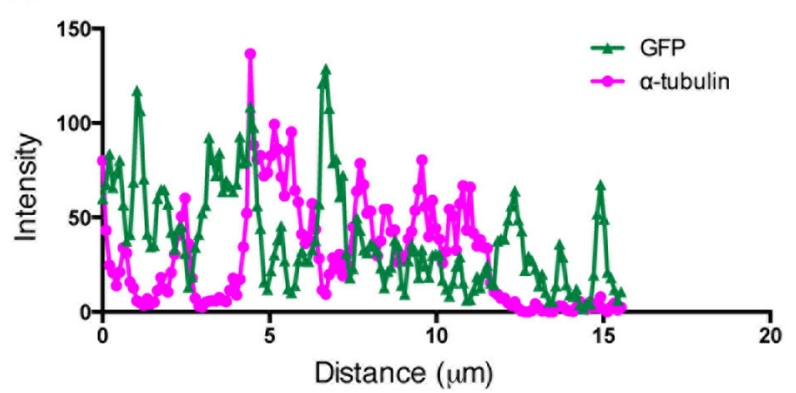

Figure 8. TBCD cooperates with Dscam in mushroom body neurons. $\boldsymbol{A}, \boldsymbol{B}$, Representative images of WT $(\boldsymbol{A})$ and Dscam ${ }^{P 1}(\boldsymbol{B})$ MARCM neuroblast clones of mushroom body neurons. $\boldsymbol{A}$, Axon of WT mushroom body neurons bifurcates into two lobes. $\boldsymbol{B}$, Dscam ${ }^{P 1}$ mutant clones showed loss of $\beta$ lobes. $\boldsymbol{C}-\boldsymbol{G}$, UAS-mCD8-GFP (green) is expressed by OK107-Gal4. Anti-Fasll antibody was used to visualize mushroom body lobes (magenta). Scale bars, $20 \mu \mathrm{m}$. D, TBCD knockdown caused loss of $\beta$ lobes. $E$, Overexpression of UAS-Dscam17.2-GFP by OK107-Gal4 caused loss of formation of mushroom body lobes. $\boldsymbol{F}$, The phenotype of Dscam overexpression was partially suppressed by knocking down of $T B C D(\boldsymbol{F})$ or $T B C D^{1}$ heterozygous background $(\boldsymbol{G})$. $\boldsymbol{H}$, Quantification of phenotypes of $\alpha$ and $\beta$ lobes. $I, J, \alpha$-tubulin staining of 22 cells transfected with UAS-GFP $(\boldsymbol{I})$ or UAS-Dscam-GFP $(\boldsymbol{J})$. Overexpression of Dscam-GFP reduced the $\alpha$-tubulin at the periphery $(\boldsymbol{J})$. Green and magenta show GFP and $\alpha$-tubulin staining, respectively. Scale bars, $7.5 \mu \mathrm{m}$. $\boldsymbol{K}$, The quantification of the reduction of $\alpha$-tubulin at the periphery; $*{ }^{* *} p=0.0024, \chi^{2}$ test. $L, M$, Drosophila primary cultured neurons. Scale bar, $10 \mu \mathrm{m}$. A magnified image of the dotted rectangle in $\boldsymbol{L}(\boldsymbol{M})$. $\boldsymbol{N}$, Intensities of GFP (green triangles) and $\alpha$-tubulin (magenta cicles) of the neurite marked in $\boldsymbol{M}$.

microtubule plus-end tracking protein orbit/MAST acts downstream of Abl in Slit repellent pathways during axon guidance (Lee et al., 2004). Netrin receptor DCC directly binds $\beta$-tubulin and modulates microtubule dynamics (Qu et al., 2013). Our study shows that TBCD binds Dscam and is required for dendrite morphogenesis in PNs and axon segregation in mushroom body neurons. We also found that Dscam overexpression reduced $\alpha$-tubulin level at the site where Dscam was localized, at the pe- riphery of S2 cells and the Dscam spots along the axons of primary cultured neurons. Moreover, Dscam overexpression caused ectopic dendrite arborization in PNs and loss of $\alpha$ and $\beta$ lobes in mushroom body neurons, which could be suppressed by reduction of TBCD. Based on these results, we propose that TBCD accumulates locally where Dscam is localized, which leads to the destruction of tubulin heterodimers. As mentioned in the previous paragraph, Dscam interacts with Dock, DSH3PX1, and Wasp 
(Worby et al., 2001). Therefore, we could not exclude the possibility that Dscam affects actin filaments via Dock/Pak signaling pathway, which changes the localization of microtubules. It is important to understand how Dscam and downstream signaling such as Dock/Pak and tubulin-folding cofactors coordinate the dynamics of actin filaments and microtubules. We also examined whether the reduction of Dscam affects microtubules by expressing myc-tagged $\beta$ Tub56D in Dscam $^{P 1}$ PNs. However, we could not observe any obvious changes in the localization and amount of $\beta$ Tub56D-myc. As the formation and maintenance of microtubule seem to be spatiotemporally regulated by many guidance receptors including Dscam, it could not be possible to detect the defects of microtubules only with Dscam knockdown. Further study is needed to investigate how Dscam regulates TBCD functions, and how Dscam mediates its effects on microtubule dynamics via TBCD.

The human ortholog of Dscam, DSCAM, is located in the Down syndrome critical region, and is implicated in the cognitive disabilities of Down syndrome (Yamakawa et al., 1998; Korbel et al., 2009). The expression level of Dscam is regulated by Fragile $X$ mental retardation protein (FMRP), which is an RNA binding protein that suppresses the expression of target genes (Cvetkovska et al., 2013; Kim et al., 2013). Silencing of the Fragile X mental retardation 1 gene encoding FMRP results in Fragile X syndrome. Both Down syndrome and Fragile X syndrome are causes for intellectual disability. We have shown that the gain-offunction phenotype of Dscam was suppressed by knockdown of TBCD. Therefore, TBCD may contribute to structural and/or functional alteration of neural circuits in Down syndrome or Fragile X syndrome.

\section{References}

Adler PN, Charlton J, Liu J (1998) Mutations in the cadherin superfamily member gene dachsous cause a tissue polarity phenotype by altering frizzled signaling. Development 125:959-968. Medline

Andrews GL, Tanglao S, Farmer WT, Morin S, Brotman S, Berberoglu MA, Price H, Fernandez GC, Mastick GS, Charron F, Kidd T (2008) Dscam guides embryonic axons by Netrin-dependent and -independent functions. Development 135:3839-3848. CrossRef Medline

Baffet AD, Benoit B, Januschke J, Audo J, Gourhand V, Roth S, Guichet A (2012) Drosophila tubulin-binding cofactor B is required for microtubule network formation and for cell polarity. Mol Biol Cell 23:3591-3601. CrossRef Medline

Bartel PL, Chien CT, Sternglanz R, Fields S (1993) Using the two-hybrid system to detect protein-protein interactions. In: Cellular interactions in development: a practical approach (Hartley DA, ed.), pp 153-179. Oxford: Oxford UP.

Bashaw GJ, Kidd T, Murray D, Pawson T, Goodman CS (2000) Repulsive axon guidance: Abelson and Enabled play opposing roles downstream of the roundabout receptor. Cell 101:703-715. CrossRef Medline

Bhamidipati A, Lewis SA, Cowan NJ (2000) ADP ribosylation factor-like protein 2 (Arl2) regulates the interaction of tubulin-folding cofactor D with native tubulin. J Cell Biol 149:1087-1096. CrossRef Medline

Brodsky MH, Steller H (1996) Positional information along the dorsalventral axis of the Drosophila eye: graded expression of the four-jointed gene. Dev Biol 173:428-446. CrossRef Medline

Bryant PJ, Huettner B, Held LI Jr, Ryerse J, Szidonya J (1988) Mutation at the fat locus interfere with cell proliferation control and epithelial morphogenesis in Drosophila. Dev Biol 129:541-554. CrossRef Medline

Chen CH, Huang H, Ward CM, Su JT, Schaeffer LV, Guo M, Hay BA (2007) A synthetic maternal-effect selfish genetic element drives population replacement in Drosophila. Science 316:597-600. CrossRef Medline

Coleman M (2005) Axon degeneration mechanisms: commonality amid diversity. Nat rev Neurosci 6:889-898. CrossRef Medline

Cunningham LA, Kahn RA (2008) Cofactor D functions as a centrosomal protein and is required for the recruitment of the $\gamma$-tubulin ring complex at centrosomes and organization of the mitotic spindle. J Biol Chem 283:7155-7165. CrossRef Medline
Cvetkovska V, Hibbert AD, Emran F, Chen BE (2013) Overexpression of Down syndrome cell adhesion molecule impairs precise synaptic targeting. Nat Neurosci 16:677-682. CrossRef Medline

Dent EW, Gupton SL, Gertler FB (2011) The growth cone cytoskeleton in axon outgrowth and guidance. Cold Spring Harb Perspect Biol 3:a001800. CrossRef Medline

Formstecher E, Aresta S, Collura V, Hamburger A, Meil A, Trehin A, Reverdy C, Betin V, Maire S, Brun C, Jacq B, Arpin M, Bellaiche Y, Bellusci S, Benaroch P, Bornens M, Chanet R, Chavrier P, Delattre O, Doye V, et al. (2005) Protein interaction mapping: a Drosophila case study. Genome Res 15:376-384. CrossRef Medline

Fromont-Racine M, Rain JC, Legrain P (1997) Toward a functional analysis of the yeast genome through exhaustive two-hybrid screens. Nat Genet 16:277-282. CrossRef Medline

Grieder NC, de Cuevas M, Spradling AC (2000) The fusome organizes the microtubule network during oocyte differentiation in Drosophila. Development 127:4253-4264. Medline

Hattori D, Demir E, Kim HW, Viragh E, Zipursky SL, Dickson BJ (2007) Dscam diversity is essential for neuronal wiring and self-recognition. $\mathrm{Na}-$ ture 449:223-227. CrossRef Medline

Hattori D, Millard SS, Wojtowicz WM, Zipursky SL (2008) Dscammediated cell recognition regulates neural circuit formation. Annu Rev Cell Dev Biol 24:597-620. CrossRef Medline

Heisenberg M (2003) Mushroom body memoir: from maps to models. Nat Rev Neurosci 4:266-275. CrossRef Medline

Hong W, Zhu H, Potter CJ, Barsh G, Kurusu M, Zinn K, Luo L (2009) Leucine-rich repeat transmembrane proteins instruct discrete dendrite targeting in an olfactory map. Nat Neurosci 12:1542-1550. CrossRef Medline

Jefferis GSE, Hummel T (2006) Wiring specificity in the olfactory system. Semin Cell Dev Biol 17:50-65. CrossRef Medline

Jefferis GS, Marin EC, Stocker RF, Luo L (2001) Target neuron prespecification in the olfactory map of Drosophila. Nature 414:204-208. CrossRef Medline

Jefferis GS, Vyas RM, Berdnik D, Ramaekers A, Stocker RF, Tanaka NK, Ito K, Luo L (2004) Developmental origin of wiring specificity in the olfactory system of Drosophila. Development 131:117-130. CrossRef Medline

Jin S, Pan L, Liu Z, Wang Q, Xu Z, Zhang YQ (2009) Drosophila tubulinspecific chaperone $\mathrm{E}$ functions at neuromuscular synapses and is required for microtubule network formation. Development 136:1571-1581. CrossRef Medline

Kim JH, Wang X, Coolon R, Ye B (2013) Dscam expression levels determine presynaptic arbor sizes in Drosophila sensory neurons. Neuron 78:827838. CrossRef Medline

Komiyama T, Luo L (2007) Intrinsic control of precise dendritic targeting by an ensemble of transcription factors. Curr Biol 17:278-285. CrossRef Medline

Komiyama T, Johnson WA, Luo L, Jefferis GS (2003) From lineage to wiring specificity: POU domain transcription factors control precise connections of Drosophila olfactory projection neurons. Cell 112:157-167. CrossRef Medline

Komiyama T, Sweeney LB, Schuldiner O, Garcia KC, Luo L (2007) Graded expression of semaphorin-1a cell-autonomously directs dendritic targeting of olfactory projection neurons. Cell 128:399-410. CrossRef Medline

Korbel JO, Tirosh-Wagner T, Urban AE, Chen XN, Kasowski M, Dai L, Grubert F, Erdman C, Gao MC, Lange K, Sobel EM, Barlow GM, Aylsworth AS, Carpenter NJ, Clark RD, Cohen MY, Doran E, Falik-Zaccai T, Lewin SO, Lott IT, et al. (2009) The genetic architecture of Down syndrome phenotypes revealed by high-resolution analysis of human segmental trisomies. Proc Natl Acad Sci U S A 106:12031-12036. CrossRef Medline

Lee T, Luo L (1999) Mosaic analysis with a repressible cell marker for studies of gene function in neuronal morphogenesis. Neuron 22:451-461. CrossRef Medline

Lee T, Lee A, Luo L (1999) Development of the Drosophila mushroom bodies: sequential generation of three distinct types of neurons from a neuroblast. Development 126:4065-4076. Medline

Lee H, Engel U, Rusch J, Scherrer S, Sheard K, Van Vactor D (2004) The microtubule plus end tracking protein Orbit/MAST/CLASP acts downstream of the tyrosine kinase $\mathrm{Abl}$ in mediating axon guidance. Neuron 42:913-926. CrossRef Medline

Li W, Guan KL (2004) The Down syndrome cell adhesion molecule 
(DSCAM) interacts with and activates Pak. J Biol Chem 279:3282432831. CrossRef Medline

Lopez-Fanarraga M, Carranza G, Bellido J, Kortazar D, Villegas JC, Zabala JC (2007) Tubulin cofactor B plays a role in the neuronal growth cone. J Neurochem 100:1680-1687. CrossRef Medline

Lu W, Fox P, Lakonishok M, Davidson MW, Gelfand VI (2013) Initial neurite outgrowth in Drosophila neurons in driven by kinesin-powered microtubule sliding. Curr Biol 23:1018-1023. CrossRef Medline

Ly A, Nikolaev A, Suresh G, Zheng Y, Tessier-Lavigne M, Stein E (2008) DSCAM is a netrin receptor that collaborates with DCC in mediating turning responses to netrin-1. Cell 133:1241-1254. CrossRef Medline

Mao Y, Rauskolb C, Cho E, Hu WL, Hayter H, Minihan G, Katz FN, Irvine KD (2006) Dachs: an unconventional myosin that functions downstream of Fat to regulate growth, affinity and gene expression in Drosophila. Development 133:2539-2551. CrossRef Medline

Marin EC, Jefferis GS, Komiyama T, Zhu H, Luo L (2002) Representation of the glomerular olfactory map in the Drosophila brain. Cell 109:243-255. CrossRef Medline

Martín L, Fanarraga ML, Aloria K, Zabala JC (2000) Tubulin folding cofactor $\mathrm{D}$ is a microtubule destabilizing protein. FEBS Lett 470:93-95. CrossRef Medline

Martin N, Jaubert J, Gounon P, Salido E, Haase G, Szatanik M, Guénet JL (2002) A missense mutation in Tbce causes progressive motor neuronopathy in mice. Nat Genet 32:443-447. CrossRef Medline

Matakatsu H, Blair SS (2004) Interactions between Fat and Dachsous and the regulation of planar cell polarity in the Drosophila wing. Development 131:3785-3794. CrossRef Medline

Matthews BJ, Kim ME, Flanagan JJ, Hattori D, Clemens JC, Zipursky SL, Grueber WB (2007) Dendrite self-avoidance is controlled by Dscam. Cell 129:593-604. CrossRef Medline

Parvari R, Hershkovitz E, Grossman N, Gorodischer R, Loeys B, Zecic A, Mortier G, Gregory S, Sharony R, Kambouris M, Sakati N, Meyer BF, Al Aqeel AI, Al Humaidan AK, Al Zanhrani F, Al Swaid A, Al Othman J, Diaz GA, Weiner R, Khan KT, et al. (2002) Mutation of TBCE causes hypoparathyroidism-retardation-dysmorphism and autosomal recessive Kenny-Caffey syndrome. Nat Genet 32:448-452. CrossRef Medline

Qu C, Dwyer T, Shao Q, Yang T, Huang H, Liu G (2013) Direct binding of TUBB3 with DCC couples netrin-1 signaling to intracellular microtubule dynamics in axon outgrowth and guidance. J Cell Sci 126:3070-3081. CrossRef Medline

Reddy GV, Rodrigues V (1999) Sibling cell fate in the Drosophila adult external sense organ lineage is specified by Prospero function, which is regulated by Numb and Notch. Development 126:2083-2092. Medline

Robinson IM, Ranjan R, Schwarz TL (2002) Synaptotagmins I and IV promote transmitter release independently of $\mathrm{Ca}^{2+}$ binding in the C2A domain. Nature 418:336-340. CrossRef Medline

Rogers SL, Rogers GC (2008) Culture of Drosophila S2 cells and their use for RNAi-mediated loss-of-function studies and immunofluorescence microscopy. Nat Protoc 3:606-611. CrossRef Medline

Sakuma C, Anzo M, Miura M, Chihara T (2014) Development of olfactory projection neuron dendrites that contribute to wiring specificity of the Drosophila olfactory circuit. Genes Genet Syst 89:17-26. CrossRef Medline

Schaefer MK, Schmalbruch H, Buhler E, Lopez C, Martin N, Guénet JL, Haase G (2007) Progressive motor neuronopathy: a critical role of the tubulin chaperone TBCE in axonal tubulin routing from the Golgi apparatus. J Neurosci 27:8779-8789. CrossRef Medline

Schmalbruch H, Jensen HJ, Bjærg M, Kamieniecka Z, Kurland L (1991) A new mouse mutant with progressive motor neuronopathy. J Neuropathol Exp Neurol 50:192-204. CrossRef Medline

Schmucker D, Clemens JC, Shu H, Worby CA, Xiao J, Muda M, Dixon JE, Zipursky SL (2000) Drosophila Dscam is an axon guidance receptor exhibiting extraordinary molecular diversity. Cell 101:671-684. CrossRef Medline
Sekine SU, Haraguchi S, Chao K, Kato T, Luo L, Miura M, Chihara T (2013) Meigo governs dendrite targeting specificity by modulating Ephrin level and $\mathrm{N}$-glycosylation. Nat Neurosci 16:683-691. CrossRef Medline

Spradling AC, Stern D, Beaton A, Rhem EJ, Laverty T, Mozden N, Misra S, Rubin GM (1999) The Berkeley Drosophila Genome Project gene disruption project: single $P$-element insertions mutating $25 \%$ of vital Drosophila genes. Genetics 153:135-177. Medline

Sweeney LB, Chou YH, Wu Z, Joo W, Komiyama T, Potter CJ, Kolodkin AL, Garcia KC, Luo L (2011) Secreted semaphorins from degenerating larval ORN axons direct adult projection neuron dendrite targeting. Neuron 72:734-747. CrossRef Medline

Tea JS, Chihara T, Luo L (2010) Histone deacetylase Rpd3 regulates olfactory projection neuron dendrite targeting via the transcription factor Prospero. J Neurosci 30:9939-9946. CrossRef Medline

Tian G, Huang Y, Rommelaere H, Vandekerckhove J, Ampe C, Cowan NJ (1996) Pathway leading to correctly folded $\beta$-tubulin. Cell 86:287-296. CrossRef Medline

Vadlamudi RK, Barnes CJ, Rayala S, Li F, Balasenthil S, Marcus S, Goodson HV, Sahin AA, Kumar R (2005) p21-activated kinase 1 regulates microtubule dynamics by phosphorylating tubulin cofactor B. Mol Cell Biol 25:3726-3736. CrossRef Medline

Vojtek AB, Hollenberg SM (1995) Ras-Rafinteraction: two-hybrid analysis. Methods Enzymol 255:331-342. CrossRef Medline

Wang J, Zugates CT, Liang IH, Lee CH, Lee T (2002) Drosophila Dscam is required for divergent segregation of sister branches and suppresses ectopic bifurcation of axons. Neuron 33:559-571. CrossRef Medline

Wang J, Ma X, Yang JS, Zheng X, Zugates CT, Lee CH, Lee T (2004) Transmembrane/juxtamembrane domain-dependent Dscam distribution and function during mushroom body neuronal morphogenesis. Neuron 43 : 663-672. CrossRef Medline

Watts RJ, Hoopfer ED, Luo L (2003) Axon pruning during Drosophila metamorphosis: evidence for local degeneration and requirement of the ubiquitin proteasome system. Neuron 38:871-885. CrossRef Medline

Wojtowicz WM, Flanagan JJ, Millard SS, Zipursky SL, Clemens JC (2004) Alternative splicing of Drosophila Dscam generates axon guidance receptors that exhibit isoform-specific homophilic binding. Cell 118:619-633. CrossRef Medline

Wong AM, Wang JW, Axel R (2002) Spatial representation of the glomerular map in the Drosophila protocerebrum. Cell 109:229-241. CrossRef Medline

Worby CA, Simonson-Leff N, Clemens JC, Kruger RP, Muda M, Dixon JE (2001) The sorting nexin, DSH3PX1, connects the axonal guidance receptor, Dscam, to the actin cytoskeleton. J Biol Chem 276:41782-41789. CrossRef Medline

Wu JS, Luo L (2006) A protocol for dissecting Drosophila melanogaster brains for live imaging or immunostaining. Nat Protoc 1:2110-2115. CrossRef Medline

Yamakawa K, Huot YK, Haendelt MA, Hubert R, Chen XN, Lyons GE, Korenberg JR (1998) DSCAM: a novel member of the immunoglobulin superfamily maps in a Down syndrome region and is involved in the development of the nervous system. Hum Mol Genet 7:227-237. CrossRef Medline

Zhan XL, Clemens JC, Neves G, Hattori D, Flanagan JJ, Hummel T, Vasconcelos ML, Chess A, Zipursky SL (2004) Analysis of Dscam diversity in regulating axon guidance in Drosophila mushroom bodies. Neuron 43: 673-686. CrossRef Medline

Zhu H, Luo L (2004) Diverse functions of $N$-cadherin in dendritic and axonal terminal arborization of olfactory projection neurons. Neuron 42 : 63-75. CrossRef Medline

Zhu H, Hummel T, Clemens JC, Berdnik D, Zipursky SL, Luo L (2006) Dendritic patterning by Dscam and synaptic partner matching in the Drosophila antennal lobe. Nat Neurosci 9:349-355. CrossRef Medline 